\title{
Industry 4.0: A Solution towards Technology Challenges of Sustainable Business Performance
}

\author{
Muhammad Haseeb ${ }^{1}{ }^{(}$, Hafezali Iqbal Hussain ${ }^{1}{ }^{(}$, , Beata Ślusarczyk ${ }^{2,3, *}$ and \\ Kittisak Jermsittiparsert ${ }^{4}$ \\ 1 Taylor's Business School (TBS), Taylor's University Lakeside Campus, 1, Jalan Taylors, Subang Jaya 47500, \\ Selangor, Malaysia; muhammad.haseeb@taylors.edu.my (M.H.); \\ hafezali.iqbalhussain@taylors.edu.my (H.I.H.) \\ 2 Faculty of Economic and Management Sciences, North-West University, Vaal Triangle Campus, P.O. Box \\ 1174, Vanderbijlpark 1900, South Africa \\ 3 The Management Faculty, Czestochowa University of Technology, al. Armii Krajowej 19 B, \\ 42-201 Czestochowa, Poland \\ 4 Social Research Institute, Chulalongkorn University, Bangkok 10330, Thailand; kittisak.j@chula.ac.th \\ * Correspondence: beata.slusarczyk@wz.pcz.pl
}

Received: 26 April 2019; Accepted: 10 May 2019; Published: 16 May 2019

\begin{abstract}
Technology adoption is always a difficult task for Small and Medium-sized Enterprises (SMEs) due to lack of resources and other market issues. Many technology challenges adversely affect the sustainable business performance of SMEs. However, the incorporation of Industry 4.0 can overcome various technology issues. The goal of Industry 4.0 is to attain an advanced level of operational effectiveness and productivity, as well as a higher level of automatization. Thus, the objective of this study is to identify the role of Industry 4.0 to promote sustainable business performance in SMEs in Thailand. A survey has been prepared to collect the data from managers of SMEs and analyzed with the help of Partial Least Square. The questionnaire was used to collect the data and questionnaires were distributed by using simple random sampling. A total of 500 questionnaires were distributed amongst the managerial staff of SMEs located in Thailand. From these distributed questionnaires, 280 were returned and 270 valid responses were found. Data were analyzed by using Partial Least Square (PLS)-Structural Equation Modeling (SEM). Findings reveal that Industry 4.0 is a key to the growth of sustainable business performance among SMEs. Elements of Industry 4.0 such as big data, Internet of Things and smart factory have a positive role in promoting information technology (IT) implementation, which contributes to sustainable business performance. Moreover, organization structure and process strengthen the positive relationship between Industry 4.0 and IT implementation.
\end{abstract}

Keywords: Industry 4.0; big data; business performance; IoT; smart factory; SMEs

\section{Introduction}

The objective of Industry 4.0 is to attain an advanced level of operational effectiveness and productivity, as well as a higher level of automatization (Ślusarczyk 2018; Thames and Schaefer 2016). As Industry 4.0 has a significant role in the production and service sectors, it has a direct relationship with performance (Imran et al. 2018; Rüßmann et al. 2015; Shrouf et al. 2014; Waschneck et al. 2016). Roblek et al. (2016) and Posada et al. (2015) have mentioned that various features of Industry 4.0 are highly connected with internet technologies as well as progressive algorithms. However, they also specify that Industry 4.0 is one of the technical procedures of value addition and effective knowledge management practices. 
Despite the extensive literature on Industry 4.0, a systematic, as well as a comprehensive review of studies on Industry 4.0, is missing (Lu 2017). Consequently, this study proposes a framework with the help of Industry 4.0 and presents the significance of this fourth revolution in Small and Medium-sized Enterprises (SMEs). It presents how Industry 4.0 is useful to overcome various technological challenges in SMEs and improves sustainable business performance. This study especially emphasizes on SMEs situated in Thailand. SMEs performance in Thailand increased in 2017 as is shown in Figure 1. In 2017, the increase in annual revenue was $44 \%$, the increase in efficiency was $42 \%$, the increase in business savings was $31 \%$, the reduction debt was $26 \%$, and the increase in investment was $25 \%$.

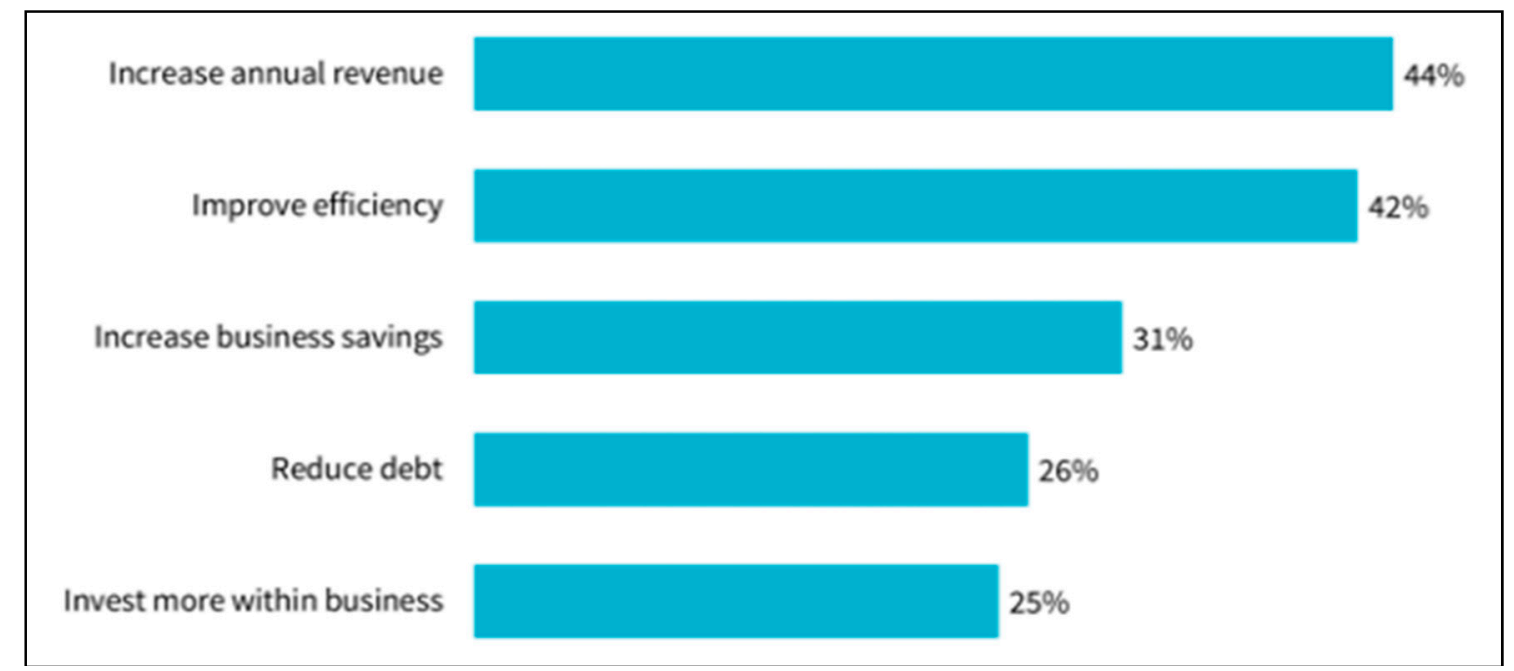

Figure 1. Thailand SMEs Performance. Source: RFI Group—Thailand SME Banking Council (2017).

SMEs are the pillar of the economy in many countries because this sector has a generous contribution to the economy through GDP (Gross Domestic Product) creation (Etuk et al. 2014; Ilegbinosa and Jumbo 2015; Lloyd 2002). Due to the nature of small-scale businesses, SMEs have various issues. One among them is a technological issue (Acs and Preston 1997; Dobrovič et al. 2018). Due to technological challenges, the performance of SMEs is not smooth. SMEs experience limitations when adopting the latest technology as it is adopted by the big organizations. This is the reason that the performance is low in the SMEs sector of Thailand due to various challenges (Chittithaworn et al. 2011). These SMEs are unable to maintain constant growth in performance. Therefore, there is a performance sustainability issue in SMEs of Thailand.

Technology adoptions are always a difficult task for small scale businesses (Burgess 2001) due to a lack of resources and other market issues. SMEs are facing issues in technology implementations (Jones and Kato 2003). These technical issues are related to the data management, data extraction and functional structure of the organization that support the new technology implementation. Technology also requires well-skilled people for proper implementation. Therefore, while adopting the latest technology, SMEs requires good human capital for better implementation.

It is possible to overcome all these issues with the help of Industry 4.0. Industry 4.0 has a positive role in resolving various issues related to data management and other technological issues. Due to these features, Industry 4.0 has a significantly positive effect on boosting products and services (Imran et al. 2018). Various Industry 4.0 factors such as big data, Internet of Things (IoT) and smart factory have a positive role in boosting sustainable performance. Therefore, incorporation of Industry 4.0 can increase sustainable business performance by resolving various technology issues. Thus, the objective of this study is to identify the role of Industry 4.0 to promote sustainable business performance in Thailand SMEs.

The current study is one of the pioneer studies which discussed the role of Industry 4.0 in technology management. Literature is available which shows the connection between Industry 4.0 and 
technology management; however, it was very rare that any study formally documented the role of Industry 4.0 to resolve the technological issues, particularly in SMEs. Therefore, this study contributed to the literature by providing valuable insights in technology management through Industry 4.0.

\section{Theoretical Outlook and Hypotheses Development}

The present industrial expansion has continued for many decades, and currently, it is in the age of Industry 4.0 (Lu 2017). The concept of Industry 4.0 was originally planned for an emerging German economic system in the year of 2011 (Vogel-Heuser and Hess 2016). Lukač (2015) mentioned that the first industrial revolution started in the last period of 18th century. This revolution was characterized by automatic production plants grounded on the water as well as steam power. The second industrial revolution began in the early 20th century, characterized by mass labor production grounded in electrical energy. The third industrial revolution started in the 1970s with the distinctive features of programmed production grounded in new technology related to the internet. Finally, the fourth industrial revolution, namely; Industry 4.0, is continuing including the features of Cyber Physical System (CPS) production, grounded in diverse data as well as knowledge combination (Lu 2017). The principal characters of CPS are based on the notion to achieve dynamic necessities of production and to advance the efficiency and competence of the whole industrial sector. Industry 4.0 includes many technologies and related patterns, cloud-based manufacturing, various resource planning activities, IoT, and social product progress (Georgakopoulos et al. 2016; Kube and Rinn 2014; Lin et al. 2016; Nagy et al. 2018; Pfeiffer 2016; Thamsen and Wulff 2016; Wan et al. 2016) and has a significant role in digital English and education (Hariharasudan and Kot 2018). Most of the features are shown in Figure 2. These features include: cloud computing, augmented reality, multilevel customer interaction, advanced algorithms with big data, smart sensors, mobile devices, IoT platforms, location detection, advanced human machine and 3D printing.

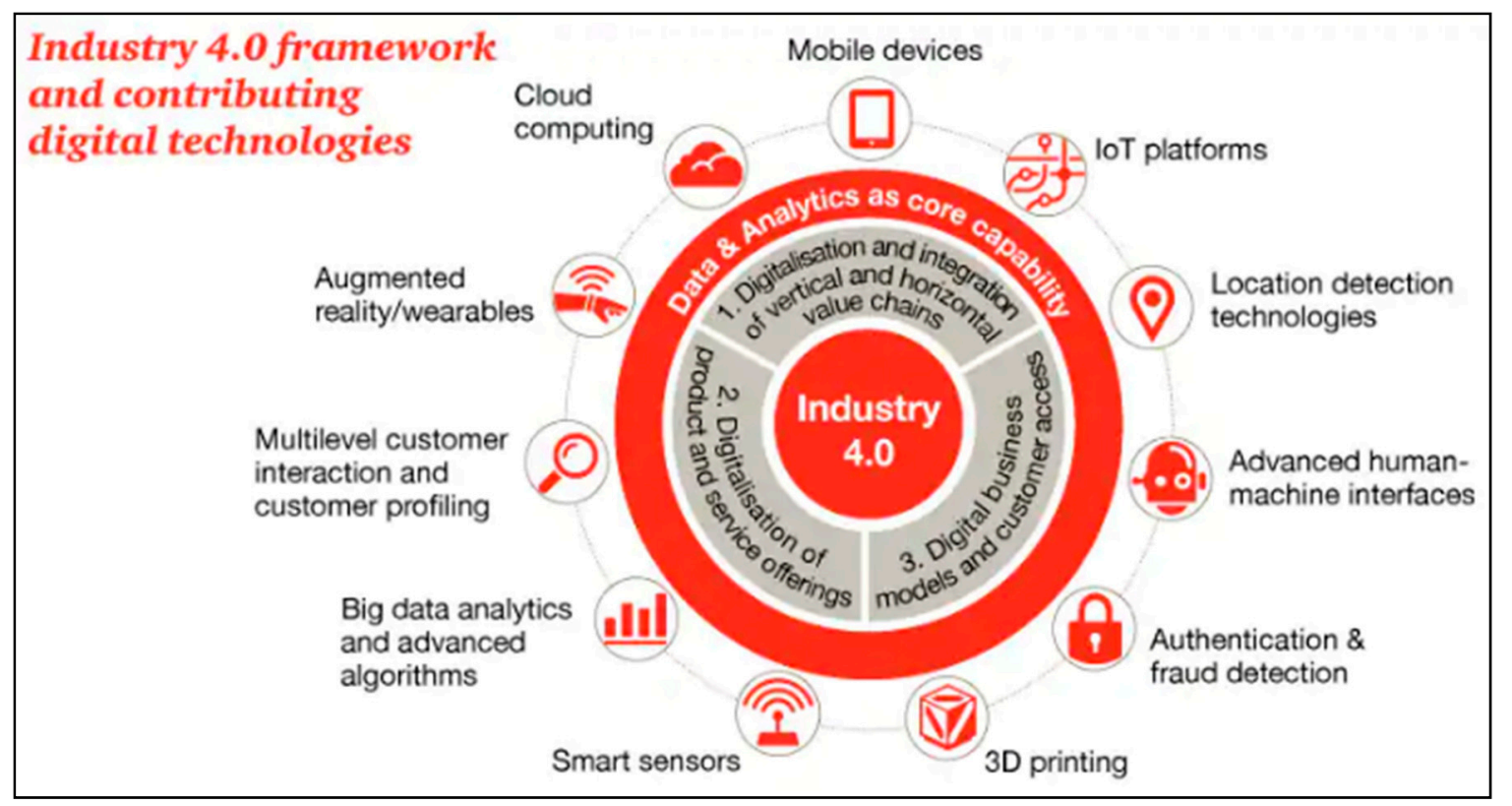

Figure 2. Industry 4.0 technology features and contributions towards digitalization. Source: Industry 4.0: Building the digital enterprise, 2016 global industry 4.0 survey, PwC engineering, \& construction 2016.

Academics have described Industry 4.0 from various viewpoints in this group. For instance, Industry 4.0 is "the integration of complex physical machinery and devices with networked sensors and software, used to predict, control and plan for better business and societal outcomes" "(Industrial Internet Consortium 2017). Henning (2013) defines Industry 4.0 as "a new level of value 
chain organization and management across the lifecycle of products". Hermann et al. (2016) describe Industry 4.0 as "a collective term for technologies and concepts of value chain organization".

This study is concerned with the three major elements of Industry 4.0 which comprise big data (BD), IoT and smart factory (SF). All these factors have a significant connection with the production and services of SMEs, and increase the performance (Imran et al. 2018). Branches of Industry 4.0 including big data (BD), IoT and smart factory (SF) can resolve technological challenges of SMEs, and these ultimately increase the sustainable business performance. Figure 3 shows how Industry 4.0 promotes the performance. It shows that five Industry 4.0 factors have significant effects on production and services. Production and services have significant effects on production and service industry performance. Therefore, it shows that Industry 4.0 increases the production and service industry performance. It is proven by the literature that Industry 4.0 has a positive influence on production and services, and it increases the performance (Imran et al. 2018).

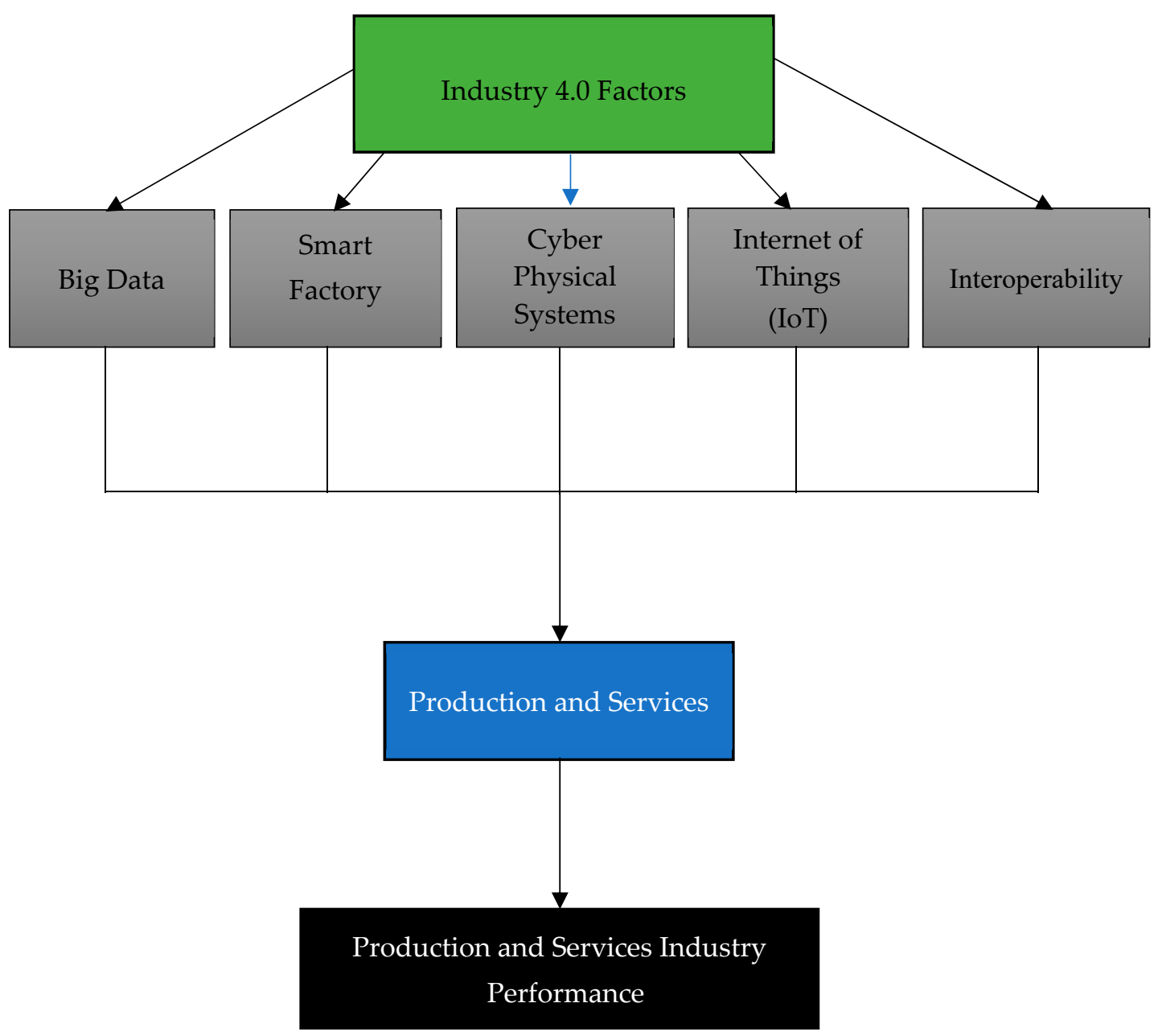

Figure 3. Industry 4.0 effect on performance. Source: Imran et al. (2018).

Big data is one of the umbrella terms for any method utilized to process a vast quantity of data, knowledge or information, including capture, safety, transmission, storing, analysis, search, confidentiality, and with data which is both structured and unstructured (Xu and Duan 2019). Big data is generally used to handle massive amounts of data (Hashem et al. 2015). The nature of big data encompasses extensive measures to identify and interpret the data into new ideas. Several scholars have used big data in previous studies. For example, Manyika et al. (2011) have mentioned that big data is a systematic visualization where "the amount of data just beyond technology's capability to store, manage, and process efficiently". Zikopoulos et al. (2013) have categorized big data by three Vs: 
volume, variety, and velocity. "Big Data is a collection of data from traditional and digital sources inside and outside your company that represents a source for ongoing discovery and analysis".

Big data generally has a better advantage to implement new technology. It has a significant relationship with technology adoption (Dhar and Mazumdar 2014; Raguseo 2018). Therefore, the implementation of big data can overcome various technology-related challenges. It provides better technology, which helps to find better ways to store data efficiently (Gu et al. 2014; Lynch 2008). Initially, there were many challenges faced by various companies regarding data storage (Langer 2011; Rashmi et al. 2013; Yang and Jia 2012) but now Industry 4.0 resolves these issues by introducing big data technology in various firms. Therefore, SMEs could resolve technology challenges with the help of an efficient big data system.

\section{Hypothesis 1 (H1). There is a relationship between big data and IT implementation.}

Many researchers have examined business information technology (IT)-related matters to find their assistance. For instance, Dos Santos et al. (1993) emphasized on the declarations of IT investments as well as advanced IT investments. Brynjolfsson and Hitt (1996) and Hitt and Brynjolfsson (1996) utilized three procedures to examine the connection between IT as well as profitability. Bharadwaj (2000) employed resource-based insight to study technology ability and company performance. Hitt and Brynjolfsson (1996) considered the business influence of enterprise source planning. The ultimate purpose of these researchers has been to comprehend whether IT could assist firms in upsurging efficiency.

In current years, IoT has developed the most significant subject in numerous industries. IoT is not only the major buzz word in businesses but is an emerging drift, an established plan, and a ground-breaking technology. Initially, Ashton (2009) projected the idea of IoT and defined IoT as exclusively recognizable consistent objects with radio-frequency identification (RFID) expertise, which has the ability to alter the world. Tang et al. (2018) have specified IoT tools which connect through the network. Few initial IoT applications been previously industrialized in health sectors, transport, home utilization, and various self-propelled industries (He et al. 2014; Joshi and Kim 2008). Industry 4.0 is based on five vital skills of IoT: RFID, cloud computing, middleware, and different IoT software applications. IoT technologies have also been extensively used in numerous industries; for instance, IoT can advance logistics as well as supply chain effectiveness by providing more comprehensive knowledge (Flügel and Gehrmann 2008). Literature predicted that IoT would reach 26 billion parts in 2020, up from 0.9 billion in 2009. Therefore, we can understand the strength of the persuading power that IoT skills can bring. Presently, different research focusing on IoT emphasizes on the expansion of IoT technologies as well as applications, whereas no such research analyzes the influence of IoT execution on sustainable business performance; therefore, this study aims to fill this gap. After examining the prior studies, it is revealed that the study carried out by Huang (2015) detected the efficiency from an external view; on the contrary, the study carried out by Huang (2016), examined the performance from an inside view. By addressing the above mentioned studies, the present study proposes to examine sustainable business performance in SMEs through IoT and other fundamentals of Industry 4.0. This research is significant for managers to implement IoT as a significant technology for sustainable business performance.

IoT has a significant relationship with the latest technologies (Fortino and Trunfio 2014; Pang 2013; Patel and Patel 2016; Suresh et al. 2014; Yun and Bu 2010), which positively affects business performance. With the latest technologies of Industry 4.0, through IoT, the technological issues among SMEs are reduced as the IoT has a significant relationship with the business process (Dachyar and Risky 2014; Del Giudice 2016; Dweekat et al. 2017). Therefore, IoT can foster business performance through different technological issues, which decrease the technological challenges in business. IoT has a splendid concept with simple terms. IoT is connected or interlinked with multiple devices via the internet. Generally, three IoT components are used in business, including (a) hardware, (b) middleware, and (c) presentation (Gubbi et al. 2013), and these lead towards business performance. All these 
components contribute to sustainable performance in SMEs. Sustainable performance always leads to better business survivability (de Sousa et al. 2018; Duygulu et al. 2016; Eisingerich and Bell 2008).

Hypothesis 2 (H2). There is a relationship between IoT and IT implementation.

Moreover, the notion of the smart factory (SF) is the combined relationship of numerous stages of original production from the preliminary planning stages to actuators in the field. The flexibility, the resource success, and the incorporation of supply, as well as demand procedures, are better in Industry 4.0; hence, factories, cities, production, equipment and things become smart (Varghese and Deepaknath 2014; Ali and Haseeb 2019). Stock and Günther (2016) explained that the key applications related to Industry 4.0 are Smart Factory (SF) and engineering the various smart products. In this field, Table 1 shows 27 studies in this group, 13 are related to smart factory and manufacturing, almost 10 debated on Smart Production, and the other four discussed Smart City. Generally, smart factory has a significant role in manufacturing, and increases sustainable business performance.

Table 1. Studies on Smart Factory and Manufacturing.

\begin{tabular}{ll}
\hline Research Category & Publication \\
\hline & Chen and Xing (2015) \\
& Kolberg and Zühlke (2015) \\
& Oses et al. (2016) \\
& Paelke (2014) \\
Sisching et al. (2015) & Rüßmann et al. (2015) \\
& Wang et al. (2016) \\
& Sanders et al. (2016) \\
& Scheuermann et al. (2015) \\
& Shafiq et al. (2016) \\
& Thames and Schaefer (2016) \\
\hline
\end{tabular}

Industry 4.0 develops factories that are extra intelligent, dynamic and flexible by preparing to manufacture with different devices, and independent arrangements (Roblek et al. 2016). Consequently, machines, as well as tools, will attain great levels of automation. Additionally, the manufacturing procedure has the volume of satisfying more multifaceted and capable standards of products (Roblek et al. 2016). Therefore, factories with smart manufacturing are the primary purpose of Industry 4.0 (Sanders et al. 2016). Agent paradigm is documented as one of the real instruments for manufacturing in a smart way, which can increase the efficiency.

Industry 4.0 could make value-added addition, which arises horizontally as well as vertically in the procedure of manufacturing (Shafiq et al. 2016; Stock and Günther 2016). Precisely, the horizontal process is combined by various value making components, from the flow of material to the supply chain of the product life cycle, while the vertical process joins in the product, human needs and equipment with a diverse combination of value formation and manufacturing schemes. According to Lasi et al. (2014), Industry 4.0 initiates manufacturing in two different directions: the application-pull process and the technology-push process. Initially, it encourages dynamic changes produced by a new group of industrial structure.

Therefore, all these features of Industry 4.0 related to smart factory have a direct effect on technology implementation, which positively affects business sustainability, as a smart factory helps to develop a small production system, which ultimately supports sustainability in production (Shrouf et al. 2014) that facilitates business performance among SMEs. As various studies prove, Industry 4.0 has a positive effect on production (Brettel et al. 2014; Weyer et al. 2015; Zawadzki and Żywicki 2016).

Hypothesis 3 (H3). There is a relationship between smart factory and IT implementation. 
From the above discussion, it is evident that Industry 4.0 factors such as big data, IoT and smart factory have a positive relationship with information technology implementation. Moreover, information technology implementation has a positive association with sustainable business performance. IT is an essential and significant resource to accomplish the business vision (Feeny and Willcocks 1998). Moshiri and Simpson (2011) point out that advances in IT can dramatically change individual and organizational performance such as transforming business organization, increasing competition, and fostering innovation. Technological advancement plays an important role in most sectors of the economy (Ali and Younes 2013; Szczepańska-Woszczyna 2014) and it significantly affects the way of doing business. In the automotive industry, IT is found crucial to making their operations responsive to customer requirements. The study by Moshiri and Simpson (2011) revealed that the use of computers by employees has a positive influence on the firm's productivity.

However, in most of the organizations, IT implementation is an issue. Nowadays, IT is extensively employed to strengthen and overcome the weaknesses of the supply chain, enhance operating efficiency, reduce operating costs, increase responsiveness, increase agility (Javanmardi et al. 2012; Chaudhry et al. 2017) reduce cycle times, develop collaborative work, expand market borders, develop seamless partnerships, improve teamwork, enhance customer relationships, proactivity on response (Fasanghari et al. 2007), increase information and product flow (Craighead and Laforge 2003), improve timeliness and accurate information flow (Kim et al. 2011). Therefore, the firm supports the utilization of IT to maintain and sustain the ability to satisfy the customer (Omar et al. 2006). The appropriate use of IT offers opportunities for the organization to improve the performance of supply chain, productivity and profitability. However, numerous companies' personnel are lacking of IT knowledge and IT skills (Fasanghari et al. 2007). Hence, it requires investments in human and social capital to build up a strong capability of IT and better implementation.

The resource-based view (RBV) of IT recommends that the IT resources in the firm can be the competitive capability of the firm. Bharadwaj (2000) points out that the firm's human IT skills, IT infrastructure, and IT reconfigurability are the firm's unique resources. Every single IT resource is unique and complex to acquire. The combination of the single IT resource created a firm's strong organizational capability (Bharadwaj 2000). The relationship between IT capability and organization performance is becoming more complex than ever before (Jeffers et al. 2008). Bharadwaj (2000) points out that various IT capabilities could be sources of competitive advantage. However, a limited number of studies have explored the RBV of IT capability, and most of the analyses to date are of a conceptual nature.

Therefore, technology implementation is the most essential step to building sustainable business performance among SMEs. Literature also shows that technology implementation and business performance have important connection with each other (Epelbaum and Martinez 2014; Malhotra 2005), increase sustainable business, and have a positive effect on overall business performance (Eisingerich and Bell 2008; Kristensen and Westlund 2004; Wang 2014). Therefore, it is needed for SMEs to develop good sustainable business practices, which will automatically lead to high performance, because it also reduces enterprise risk (Hameed et al. 2017). According to the previous literature, it is clear that IT is available in organizations; however, the implementation of IT is missing, and it shows negative results towards sustainable business performance. Therefore, implementation is most crucial factor in the IT system to get better results.

Hypothesis 4 (H4). There is a relationship between IT implementation and sustainable business performance.

Hypothesis 5 (H5). IT implementation mediates the relationship between big data and sustainable business performance.

Hypothesis 6 (H6). IT implementation mediates the relationship between IoT and sustainable business performance. 
Hypothesis 7 (H7). IT implementation mediates the relationship between smart factory and sustainable business performance.

Consistent with Industry 4.0 and IT implementation, the organization structure and process (SP) should be supportive of adopting various technological changes. In the current study, structures and processes are grounded with how the organization categorizes for IT. It includes IT expansion, distribution of IT advantages, structures and the mechanisms for transporting business and IT organization together (Peppard and Ward 2004). Structures and processes are also measured as the process by which organizational movement takes place. Insufficient or unsuitable structures and processes can negatively affect the success of IT in firms (Delone and McLean 2003).

The IT organization advances the applications in reply to business requirements or grounded on what it thinks the business necessitates. Suitable structures and processes are essential to enable IT/business incorporation. Brown and Magill (1994) have worked on evolving a model of antecedents in the alignment of the function with the organization, yet that model has had exclusive emphasis on structural dimensions, which has overlooked the importance of total organizational involvement in IT. Therefore, the structure and process of the organization have an important role in technology implementation. Good organization structure and process lead to better strategic alignment, which leads to the better management processes, strategy, technology, individual employee role and better technology implementation (Al-Majali 2011) as it is shown in Figure 4.

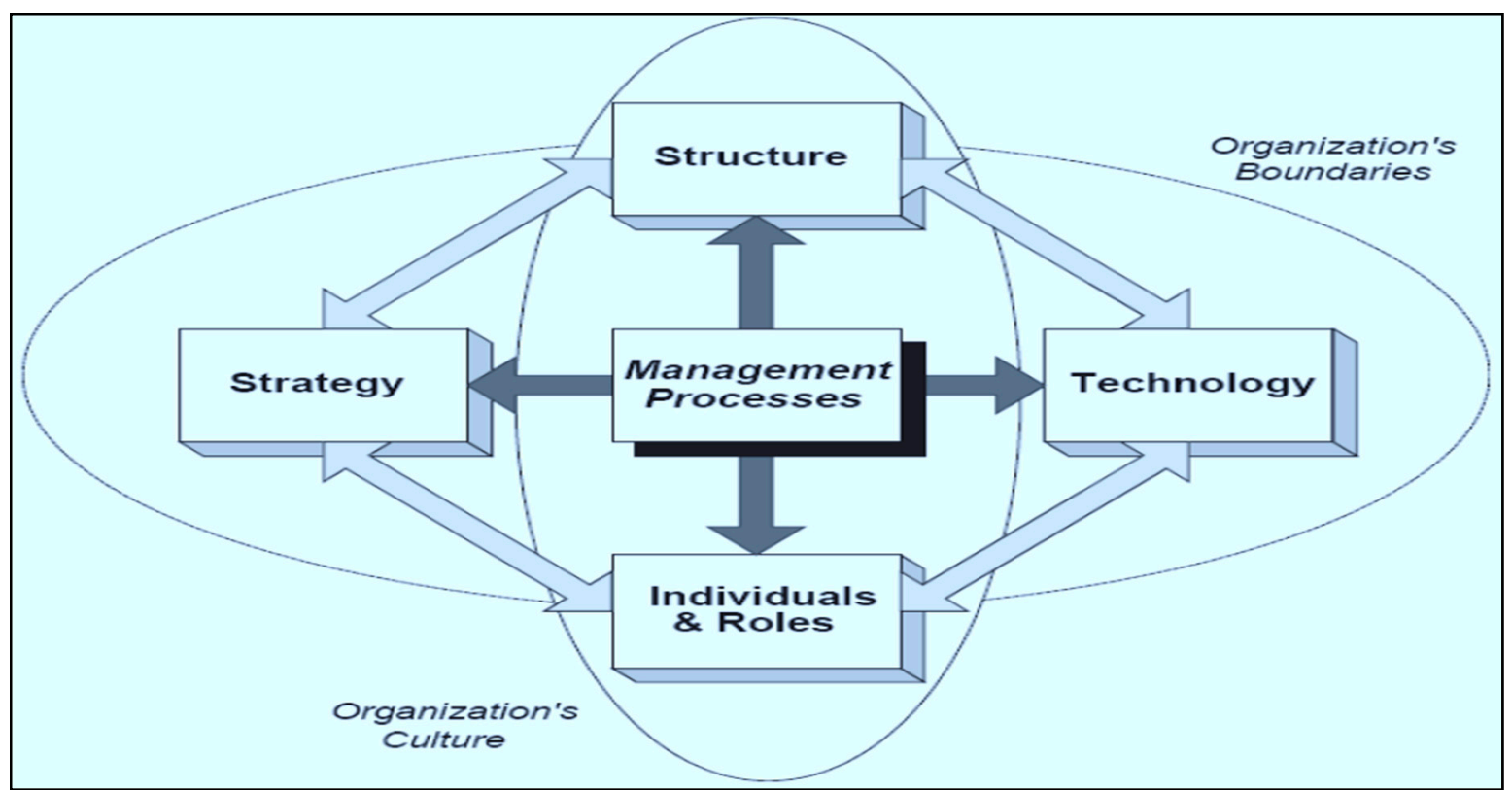

Figure 4. Massachusetts Institute of Technology Model. Source: Al-Majali (2011).

Henderson and Venkatraman (1999) explained that alignment includes compatibility addition among business strategy, IT strategy, and IT infrastructure and procedures. "Alignment has been defined as the degree to which the IT mission, objectives, and plans support and are maintained by their business counterparts (Reich and Benbasat 1990, 1996)". Marginson et al. (2000) designated alignment as the fit of IT strategies with different business plans as well as goals. However, Kanellis et al. (1999) specified that alignment is appropriate between its strategy and organization and, technology, structure, procedures as well as environment.

Various studies proved that technology implementation has a significant relationship with business performance (Brynjolfsson and Hitt 2000; Ghobakhloo and Hong 2014; Ho 1996; Hoque et al. 2011; Kihara et al. 2016) and structure and process of an organization shows a strong relationship with IT implementation (Heracleous and Barrett 2001) and it also a has relationship with strategy 
implementation (Skivington and Daft 1991). It also has an effect on strategy or technology implementation from Industry 4.0 that positively affects business performance among SMEs. If the organization structure and process is not supportive of adopting big data technology, it influences negatively. On the other hand, if the organizational structure is not supportive of adopting technology related to Internet of Things (IoT) and smart factory, and it also influences negatively on the adoption of new technology and sustainable business performance. Therefore, organization structure and process should be supportive of accepting and implementing new technology related to big data, Internet of Things (IoT) and smart factory which will lead to better sustainable business performance among SMEs. Therefore, organization structure and processes have an influence on the relationship between Industry 4.0 and IT implementation.

Hypothesis $8 \mathbf{( H 8 )}$. There is a relationship between structure and processes, and IT implementation.

Hypothesis 9 (H9). Structure and processes moderate the relationship between big data and IT implementation.

Hypothesis 10 (H10). Structure and processes moderate the relationship between IoT and IT implementation.

Hypothesis 11 (H11). Structure and processes moderate the relationship between smart factory and IT implementation.

\section{Methodology}

The objective of this study is to identify the role of Industry 4.0 to promote sustainable business performance in Thai SMEs. Three major elements of Industry 4.0 were considered, namely; big data, IoT and smart factory. Moreover, organization structure, process and technology implementation were also considered. Figure 5 shows that how Industry 4.0 factors contribute towards sustainable business performance.

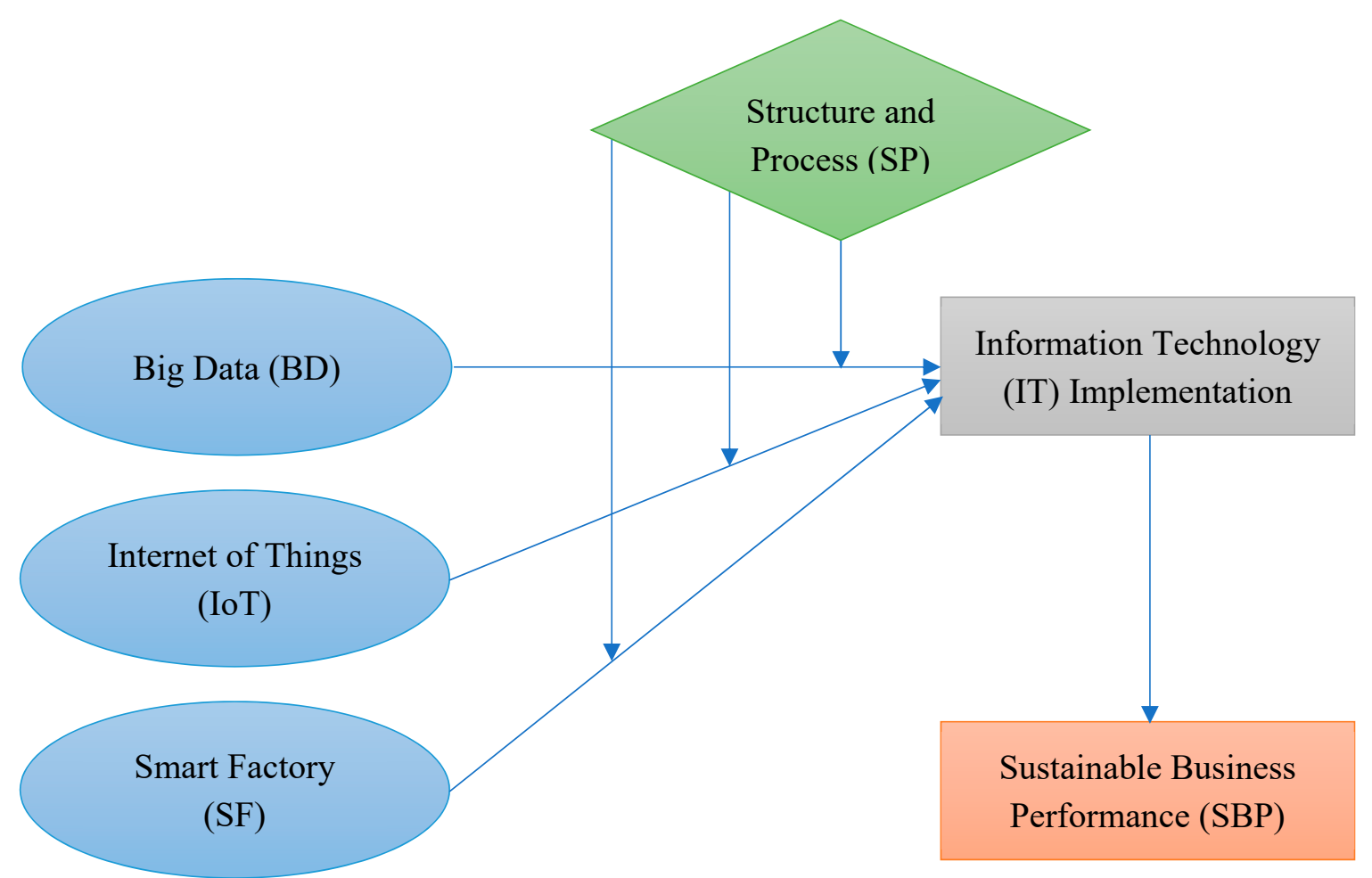

Figure 5. Theoretical framework of the study showing the contribution of Industry 4.0 towards sustainable business performance. 
Figure 6 comprehensively shows the various concerns involved in the research design. This research design was initialized by a discussion of the details of this study, which comprised the population of this study, unit of analysis, and sampling design. The discussion of research design was followed by the instrument development which involved the design, structure, and measurement scale of the survey questionnaire. The pretesting and pilot study were carried out before the data collection, the methodology to test, the content validity and reliability. The data collection methodology was finalized about the method, procedure, and period of data collection of this study. Analytical methodology and interpretation were discussed as well as the hypotheses testing of this study.

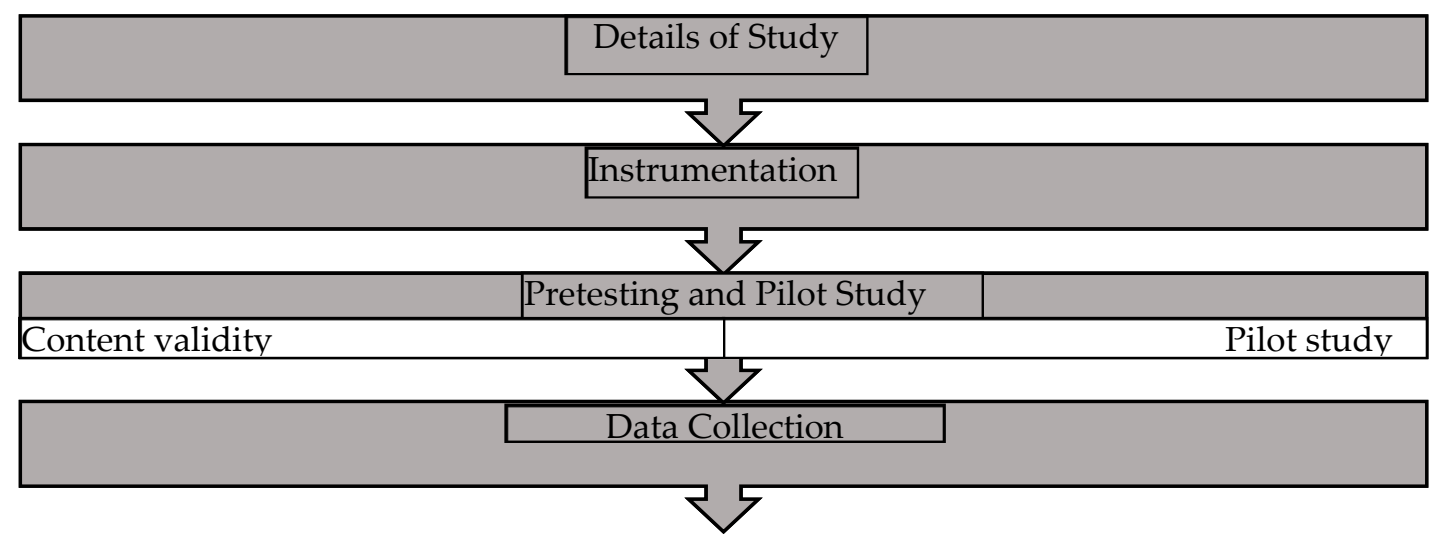

\begin{tabular}{|c|c|}
\hline \multicolumn{2}{|c|}{ Analytical Methodology and Interpretation } \\
\hline SPSS & PLS-SEM \\
\hline
\end{tabular}

Figure 6. Flow Chart for Quantitative Research Design. Source: Sekaran and Bougie (2010, p. 68).

In this study, by following the cross-sectional research design, a survey was carried out. First of all, the pilot study was performed, and 70 responses were used. Results of the pilot study showed that the questionnaire had a satisfactory level of reliability and validity. After the pilot study, a total of 500 questionnaires was distributed among the managerial staff of SMEs located in Thailand.

The survey was carried out with the help of the 7-point Likert scale. The questionnaire was divided in to two major sections. The first major section was based on the respondent's profile including, age of respondents, income of respondents, gender of respondents, education of respondents and marital status of respondents. The second section was based on key scale items of each variables.

SMEs (small and medium-sized enterprises) in the textile and clothing was considered to collect the data. Managers which were related to the technology management of these SMEs were selected to receive a response. From these 500 distributed questionnaires, 280 were returned, and 10 questionnaires were incomplete and excluded from the analysis. The response rate was $56 \%$. Thus, 270 valid responses were found. The valid response rate was $54 \%$. Therefore, 270 responses were used to analyze the data. Data were collected from October 2018 to December 2018.

All the measures were adapted from previous studies. Measures for Industry 4.0 factors; big data, IoT and smart factory were adapted from Imran et al. (2018). IT implementation was measured with the help of five items, which were adapted from Sabherwal and Kirs (1994). Measures for sustainable business performance were adapted from Nawanir (2016). Finally, the measures for structure and process were measured by adapting the scale from Peppard and Ward (2004).

\section{Data Analysis and Results}

This study used Partial Least Square (PLS) to analyze the data. However, before analyzing the data, first of all, a preliminary analysis was conducted to investigate missing value, outlier, mean, 
median, standard deviation, and whether the data is normal or non-normal. This analysis is shown in Table 2. The data has no missing value and free from an outlier. Moreover, it is found that data is normally distributed.

Table 2. Preliminary Analysis.

\begin{tabular}{|c|c|c|c|c|c|c|c|c|c|}
\hline & No. & Missing & Mean & Median & Min & $\operatorname{Max}$ & SD & Kurtosis & Skewness \\
\hline BD1 & 1 & 0 & 3.231 & 3 & 1 & 7 & 1.51 & -0.449 & 0.131 \\
\hline BD2 & 2 & 0 & 3.203 & 3 & 1 & 7 & 1.817 & -0.617 & 0.479 \\
\hline BD3 & 3 & 0 & 3.476 & 3 & 1 & 7 & 1.857 & -0.732 & 0.365 \\
\hline BD4 & 4 & 0 & 3.476 & 3 & 1 & 7 & 1.904 & -0.747 & 0.445 \\
\hline BD5 & 5 & 0 & 3.491 & 3 & 1 & 7 & 1.692 & -0.373 & 0.337 \\
\hline IoT1 & 6 & 0 & 3.443 & 3 & 1 & 7 & 1.83 & -0.709 & 0.289 \\
\hline IoT2 & 7 & 0 & 3.429 & 3 & 1 & 7 & 1.809 & -0.858 & 0.166 \\
\hline IoT3 & 8 & 0 & 3.608 & 4 & 1 & 7 & 1.856 & -0.722 & 0.269 \\
\hline IoT4 & 9 & 0 & 3.675 & 3 & 1 & 7 & 1.861 & -0.737 & 0.35 \\
\hline IoT5 & 10 & 0 & 3.59 & 3 & 1 & 7 & 1.932 & -0.72 & 0.432 \\
\hline SF1 & 11 & 0 & 3.514 & 3 & 1 & 7 & 1.887 & -0.701 & 0.425 \\
\hline SF2 & 12 & 0 & 3.528 & 3 & 1 & 7 & 1.808 & -0.517 & 0.393 \\
\hline SF3 & 13 & 0 & 3.533 & 3 & 1 & 7 & 1.882 & -0.729 & 0.348 \\
\hline SF4 & 14 & 0 & 3.425 & 3 & 1 & 7 & 1.759 & -0.37 & 0.493 \\
\hline SF5 & 15 & 0 & 3.467 & 3 & 1 & 7 & 1.912 & -0.903 & 0.249 \\
\hline ITI1 & 16 & 0 & 3.396 & 3 & 1 & 7 & 1.797 & -0.557 & 0.379 \\
\hline ITI2 & 17 & 0 & 3.604 & 3 & 1 & 7 & 1.795 & -0.619 & 0.318 \\
\hline ITI3 & 18 & 0 & 3.042 & 3 & 1 & 7 & 1.432 & 0.117 & 0.653 \\
\hline ITI4 & 19 & 0 & 3.118 & 3 & 1 & 7 & 1.467 & 0.727 & 0.96 \\
\hline ITI5 & 20 & 0 & 3.208 & 3 & 1 & 7 & 1.419 & 0.948 & 0.935 \\
\hline SBP1 & 21 & 0 & 3.151 & 3 & 1 & 7 & 1.423 & 0.58 & 0.79 \\
\hline SBP2 & 22 & 0 & 3.071 & 3 & 1 & 7 & 1.377 & 0.533 & 0.68 \\
\hline SBP3 & 23 & 0 & 3.137 & 3 & 1 & 7 & 1.452 & 0.519 & 0.718 \\
\hline SBP4 & 24 & 0 & 3.09 & 3 & 1 & 7 & 1.413 & 0.558 & 0.79 \\
\hline SBP5 & 25 & 0 & 3.042 & 3 & 1 & 7 & 1.409 & -0.157 & 0.444 \\
\hline SP1 & 26 & 0 & 3.113 & 3 & 1 & 7 & 1.352 & 0.427 & 0.624 \\
\hline SP2 & 27 & 0 & 3.071 & 3 & 1 & 7 & 1.38 & 0.4 & 0.696 \\
\hline SP3 & 28 & 0 & 3.104 & 3 & 1 & 7 & 1.427 & 0.56 & 0.807 \\
\hline SP4 & 29 & 0 & 3.16 & 3 & 1 & 7 & 1.34 & -0.043 & 0.498 \\
\hline SP5 & 30 & 0 & 3.104 & 3 & 1 & 7 & 1.306 & 0.022 & 0.459 \\
\hline
\end{tabular}

After preliminary analysis, data reliability and validity were assessed with the help of PLS-SEM. In this case, Cronbach alpha and Composite Reliability (CR) were examined to check the reliability. In the case of validity, convergent validity and discriminant validity were examined. Figure 7 shows the measurement model assessment in which all items have loadings above 0.7 . Table 3 shows the factor loadings. Table 4 shows that both CR and Cronbach alpha are also above 0.7.

According to Hair et al. (2017), all the items must have factor loadings above 0.7. The items having factor loadings less than 0.7 should be deleted. In this study, none of the items has factor loadings below 0.7. Thus, all the items have been retained. Discriminant validity is given in Table 5, and it is achieved with the help of AVE square root. 


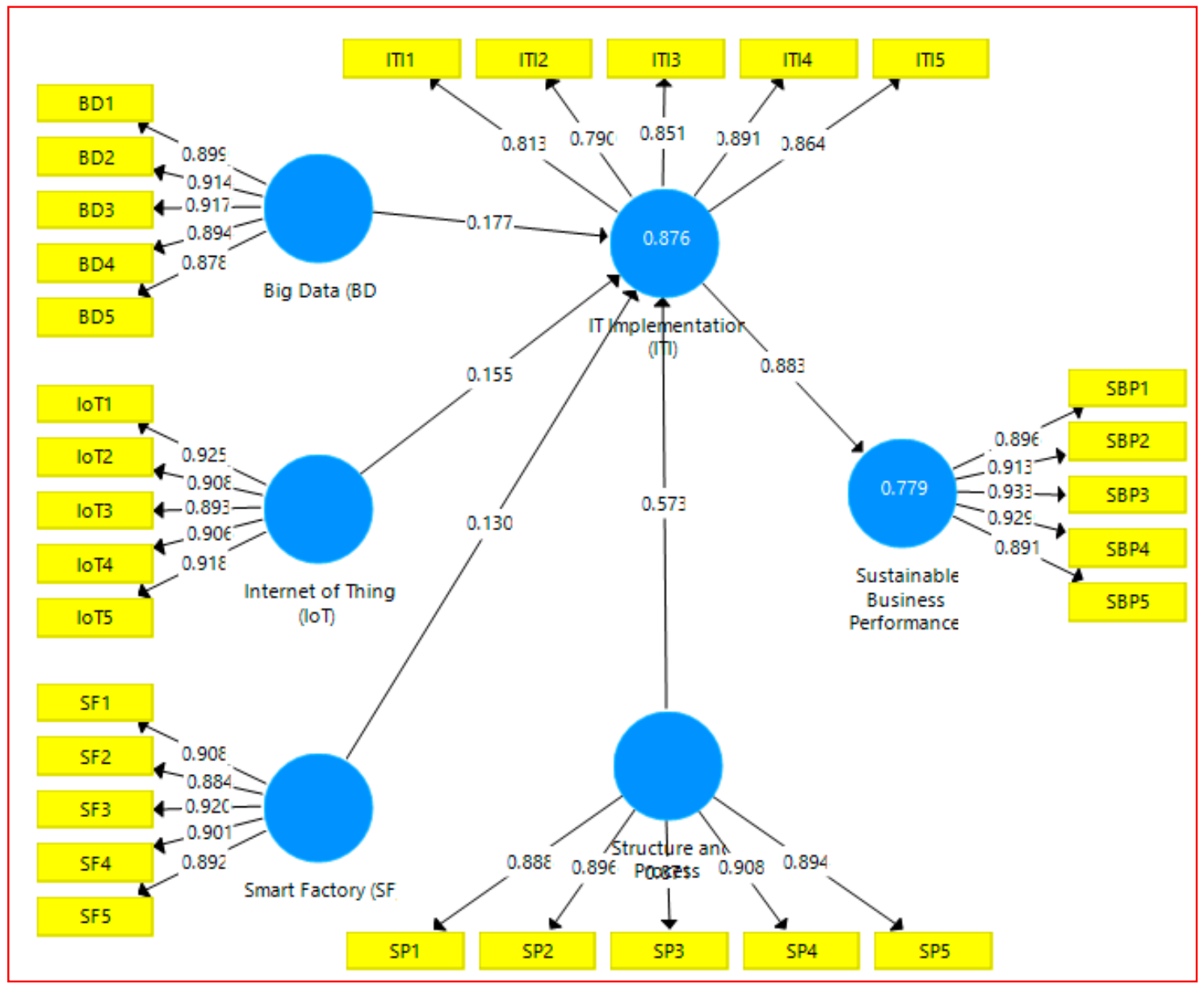

Figure 7. Measurement Model Assessment.

After the assessment of reliability and validity, the study carried out further analysis for hypotheses testing. Figure 8 indicates direct hypotheses testing and Table 6 shows the results. In this study, a minimum level of $t$-value is 1.96 to accept or reject the hypotheses. Results show that all the direct relationships have a $t$-value above 1.96, which indicates a significant relationship. Moreover, all the relationships have a positive beta value, which shows a direct relationship. Therefore, big data, IoT and smart factory have a positive relationship with IT implementation. In addition, structure and processes also have a positive relationship with IT implementation. The relationship between big data and IT implementation found $\beta$-value 0.177 and $t$-value 2.151 which is supported. The effect of IT implementation on sustainable business performance found $\beta$-value 0.883 and $t$-value 64.274 which is also supported. The effect of IoT and smart factory on IT implementation found $\beta$-value $0.115,0.130$ and $t$-value 1.979 and 2.546, thus, these hypotheses are also accepted. Finally, structure and process also found significant positive relationship with IT implementation with $\beta$-value 0.573 and $t$-value 18.655.

Consistent with the direct effect, indirect effects are also significant. The indirect effect is shown in Table 7. In line with direct effect, to examine the indirect effect, $t$-value 1.96 is considered. All the mediation hypotheses are accepted. Therefore, IT implementation is a mediating variable between Industry 4.0 and sustainable business performance. 
Table 3. Factor Loadings.

\begin{tabular}{|c|c|c|c|c|c|c|}
\hline & $\begin{array}{l}\text { Big Data } \\
\text { (BD) }\end{array}$ & $\begin{array}{c}\text { IT Implementation } \\
\text { (ITI) }\end{array}$ & $\begin{array}{l}\text { Internet of } \\
\text { Things (IoT) }\end{array}$ & $\begin{array}{c}\text { Latent } \\
\text { Variable } 1\end{array}$ & $\begin{array}{c}\text { Smart } \\
\text { Factory (SF) }\end{array}$ & $\begin{array}{l}\text { Sustainable Business } \\
\text { Performance }\end{array}$ \\
\hline BD1 & 0.899 & & & & & \\
\hline BD2 & 0.914 & & & & & \\
\hline BD3 & 0.917 & & & & & \\
\hline BD4 & 0.894 & & & & & \\
\hline BD5 & 0.878 & & & & & \\
\hline ITI1 & & 0.813 & & & & \\
\hline ITI2 & & 0.790 & & & & \\
\hline ITI3 & & 0.851 & & & & \\
\hline ITI4 & & 0.891 & & & & \\
\hline ITI5 & & 0.864 & & & & \\
\hline IoT1 & & & 0.925 & & & \\
\hline IoT2 & & & 0.908 & & & \\
\hline IoT3 & & & 0.893 & & & \\
\hline IoT4 & & & 0.906 & & & \\
\hline IoT5 & & & 0.918 & & & \\
\hline SBP1 & & & & 0.896 & & \\
\hline SBP2 & & & & 0.913 & & \\
\hline SBP3 & & & & 0.933 & & \\
\hline SBP4 & & & & 0.929 & & \\
\hline SBP5 & & & & 0.891 & & \\
\hline SF1 & & & & & 0.908 & \\
\hline SF2 & & & & & 0.884 & \\
\hline SF3 & & & & & 0.920 & \\
\hline SF4 & & & & & 0.901 & \\
\hline SF5 & & & & & 0.892 & \\
\hline SP1 & & & & & & 0.888 \\
\hline SP2 & & & & & & 0.896 \\
\hline SP3 & & & & & & 0.871 \\
\hline SP4 & & & & & & 0.908 \\
\hline SP5 & & & & & & 0.894 \\
\hline
\end{tabular}

Table 4. Reliability and Convergent Validity.

\begin{tabular}{lcccc}
\hline & $\boldsymbol{\alpha}$ & rho_A & CR & (AVE) \\
\hline Big Data (BD) & 0.942 & 0.942 & 0.955 & 0.811 \\
IT Implementation (ITI) & 0.898 & 0.903 & 0.924 & 0.710 \\
Internet of Things (IoT) & 0.948 & 0.949 & 0.960 & 0.828 \\
Structure and Process (SP) & 0.935 & 0.936 & 0.951 & 0.794 \\
Smart Factory (SF) & 0.942 & 0.943 & 0.956 & 0.812 \\
Sustainable Business Performance & 0.950 & 0.950 & 0.961 & 0.833 \\
\hline
\end{tabular}

Table 5. Discriminant Validity.

\begin{tabular}{lcccccc}
\hline & (BD) & (ITI) & (IoT) & (SF) & (SP) & (SBP) \\
\hline Big Data (BD) & 0.900 & & & & & \\
IT Implementation (ITI) & 0.826 & 0.843 & & & & \\
Internet of Things (IoT) & 0.838 & 0.807 & 0.910 & & & \\
Smart Factory (SF) & 0.726 & 0.799 & 0.838 & 0.901 & & \\
Structure and Process (SP) & 0.667 & 0.772 & 0.634 & 0.627 & 0.891 & \\
Sustainable Business Performance (SBP) & 0.721 & 0.783 & 0.683 & 0.662 & 0.709 & 0.913 \\
\hline
\end{tabular}




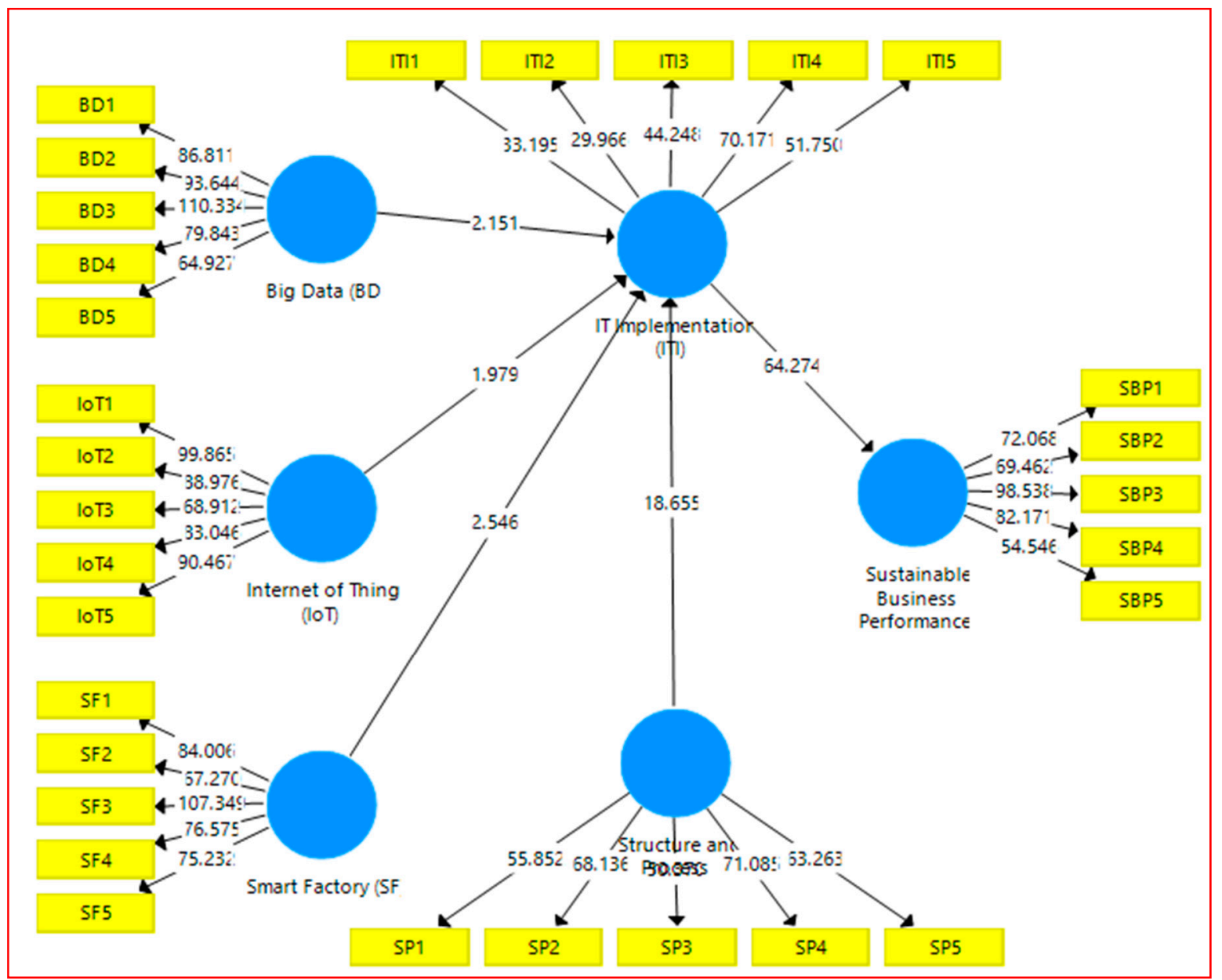

Figure 8. Structural Model Assessment.

Table 6. Direct Effect Results.

\begin{tabular}{lccccc}
\hline & $(\mathbf{O})$ & $\mathbf{( M )}$ & $\mathbf{( S T D E V )}$ & T Statistics & $p$ Values \\
\hline $\begin{array}{l}\text { Big Data (BD) -> IT } \\
\text { Implementation (ITI) }\end{array}$ & 0.177 & 0.176 & 0.082 & 2.151 & 0.032 \\
\hline $\begin{array}{l}\text { IT Implementation (ITI) -> } \\
\begin{array}{l}\text { Sustainable Business } \\
\text { Performance (SBP) }\end{array}\end{array}$ & 0.883 & 0.883 & 0.014 & 64.274 & 0.000 \\
\hline $\begin{array}{l}\text { Internet of Things (IoT) -> IT } \\
\text { Implementation (ITI) }\end{array}$ & 0.155 & 0.157 & 0.078 & 1.979 & 0.048 \\
\hline $\begin{array}{l}\text { Smart Factory (SF) -> IT } \\
\text { Implementation (ITI) }\end{array}$ & 0.130 & 0.129 & 0.052 & 2.546 & 0.021 \\
\hline $\begin{array}{l}\text { Structure and Process (SP) -> IT } \\
\text { Implementation (ITI) }\end{array}$ & 0.573 & 0.575 & 0.031 & 18.655 & 0.000 \\
\hline
\end{tabular}


Table 7. Mediation Effect.

\begin{tabular}{lccccc}
\hline & (O) & (M) & SD & T Statistics & $p$ Values \\
\hline $\begin{array}{l}\text { Big Data (BD) -> IT Implementation (ITI) } \\
\text {-> Sustainable Business Performance }\end{array}$ & 0.156 & 0.155 & 0.073 & 2.149 & 0.032 \\
\hline $\begin{array}{l}\text { Internet of Things (IoT) -> IT } \\
\begin{array}{l}\text { Implementation (ITI) -> Sustainable } \\
\text { Business Performance }\end{array}\end{array}$ & 0.137 & 0.139 & 0.069 & 1.972 & 0.049 \\
\hline $\begin{array}{l}\text { Smart Factory (SF) -> IT Implementation } \\
\text { (ITI) -> Sustainable Business Performance }\end{array}$ & 0.115 & 0.114 & 0.026 & 4.391 & 0.000 \\
\hline
\end{tabular}

Table 8 highlights the results of the moderation effect and Figure 9 shows the structural model for moderation effect through PLS. The same criteria were followed, and the minimum level of $t$-value (1.96) is considered. It is found that structure and processes are a moderating variable between big data and IT implementation with $\beta$-value 0.039 and $t$-value 2.492 . It is also found that structure and processes are a moderating variable between smart factory and IT implementation with $\beta$-value 0.048 and $t$-value 2.519. However, the moderation effect is insignificant between IoT and IT implementation. Thus, hypothesis 9 is not supported as the $\beta$-value 0.036 and $t$-value 0.322 .

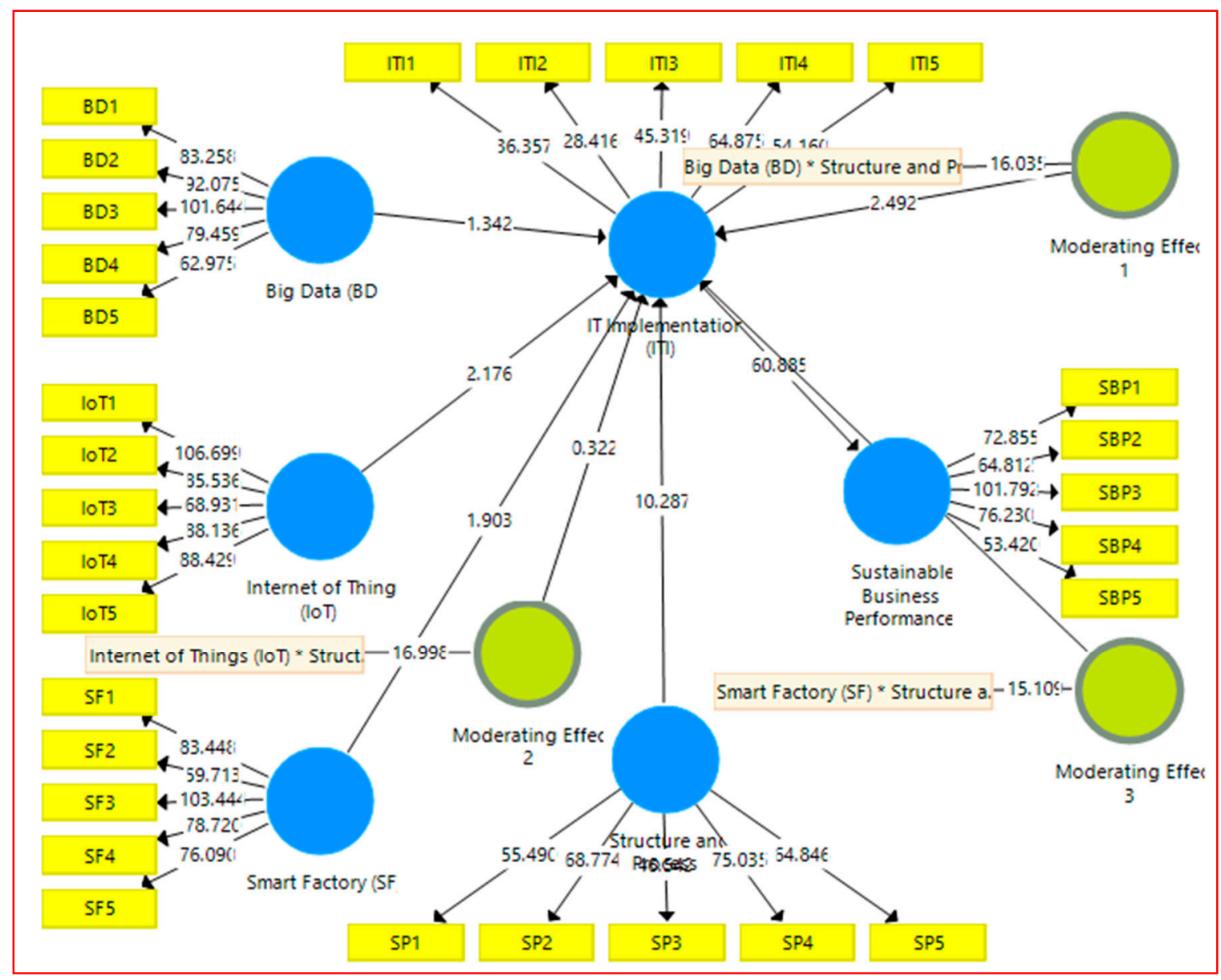

Figure 9. Structural Model Assessment (Moderation Effect).

Moreover, Figure 7 highlights that $r$-square $\left(\mathrm{R}^{2}\right)$ value is 0.779 for sustainable business performance. Thus, all the constructs have the tendency to bring $77.9 \%$ change in sustainable business performance which is good (Chin 1998). Additionally, predictive relevance $\left(\mathrm{Q}^{2}\right)$ shows the quality of the model, should be above zero (Chin 1998), and it is shown in Table 9. 
Table 8. Moderation Effect.

\begin{tabular}{lccccc}
\hline & (O) & (M) & SD & T Statistics & $p$ Values \\
\hline Moderating Effect 1 -> IT Implementation (ITI) & 0.039 & 0.035 & 0.016 & 2.492 & 0.021 \\
Moderating Effect 2 -> IT Implementation (ITI) & 0.036 & 0.035 & 0.113 & 0.322 & 0.748 \\
Moderating Effect 3 -> IT Implementation (ITI) & 0.048 & 0.056 & 0.019 & 2.519 & 0.020 \\
\hline
\end{tabular}

Table 9. Predictive Relevance $\left(\mathrm{Q}^{2}\right)$.

\begin{tabular}{cccc}
\hline & SSO & SSE & $\mathbf{Q}^{\mathbf{2}}$ (=1 - SSE/SSO) \\
\hline IT Implementation (ITI) & 1060.00 & 444.819 & 0.58 \\
Sustainable Business Performance & 1060.00 & 416.76 & 0.607 \\
\hline
\end{tabular}

\section{Discussion}

The results of the study discovered that Industry 4.0 has a significant contribution to overcome technological challenges and increase sustainable business performance. Industry 4.0 factors, big data, IoT and smart factory, have an important effect on sustainable business performance in Thai SMEs. These results are consistent with the literature. All these factors have a significant relationship with products and services, and these increase the performance (Imran et al. 2018). It is proven by various studies that Industry 4.0 has a positive effect on production (Brettel et al. 2014; Weyer et al. 2015; Zawadzki and Żywicki 2016), which increases the business performance.

Generally, big data has a better advantage to implement new technology. It has a significant relationship with technology adoption (Dhar and Mazumdar 2014; Raguseo 2018). The same results are found by the current study. Big data has a positive effect on IT implementation. Therefore, the implementation of big data can overcome various technology-related challenges. It delivers better technology, which promotes better ways to store data efficiently (Gu et al. 2014; Lynch 2008). Consequently, SMEs must ensure better big data technology in their companies.

Moreover, it is found that IoT also has a significant contribution towards technology implementation in SMEs. Introduction of IoT technology increases IT implementation as it is revealed by the literature that IoT has a significant relationship with latest technologies (Fortino and Trunfio 2014; Pang 2013; Patel and Patel 2016; Suresh et al. 2014; Yun and Bu 2010), which affect positively on business performance. For that reason, a better introduction of IoT technology is most crucial in Thai SMEs.

Furthermore, consistent with the results of the current study, Stock and Günther (2016) have clarified that the key applications of Industry 4.0 are smart factory (SF), which manufactures various smart products. This study also found that IT implementation has a positive effect on sustainable business performance. As it is explained by the literature that technology implementation and business performance has important connection with each other (Epelbaum and Martinez 2014; Malhotra 2005). Moshiri and Simpson (2011) mentioned that advancement in IT can dramatically change individual and organizational performance such as transform business organization, increase competition, and foster innovation. Technological advancement plays a significant role in various sectors of the economy (Ali and Younes 2013; Shpak et al. 2017; Šavareikienè and Rasa 2018; Durana et al. 2019). So, better implementation of IT has major role in boosting sustainable business performance. Additionally, the moderation effect of structure and processes is also examined by the current study that is shown in Figures 10 and 11. 


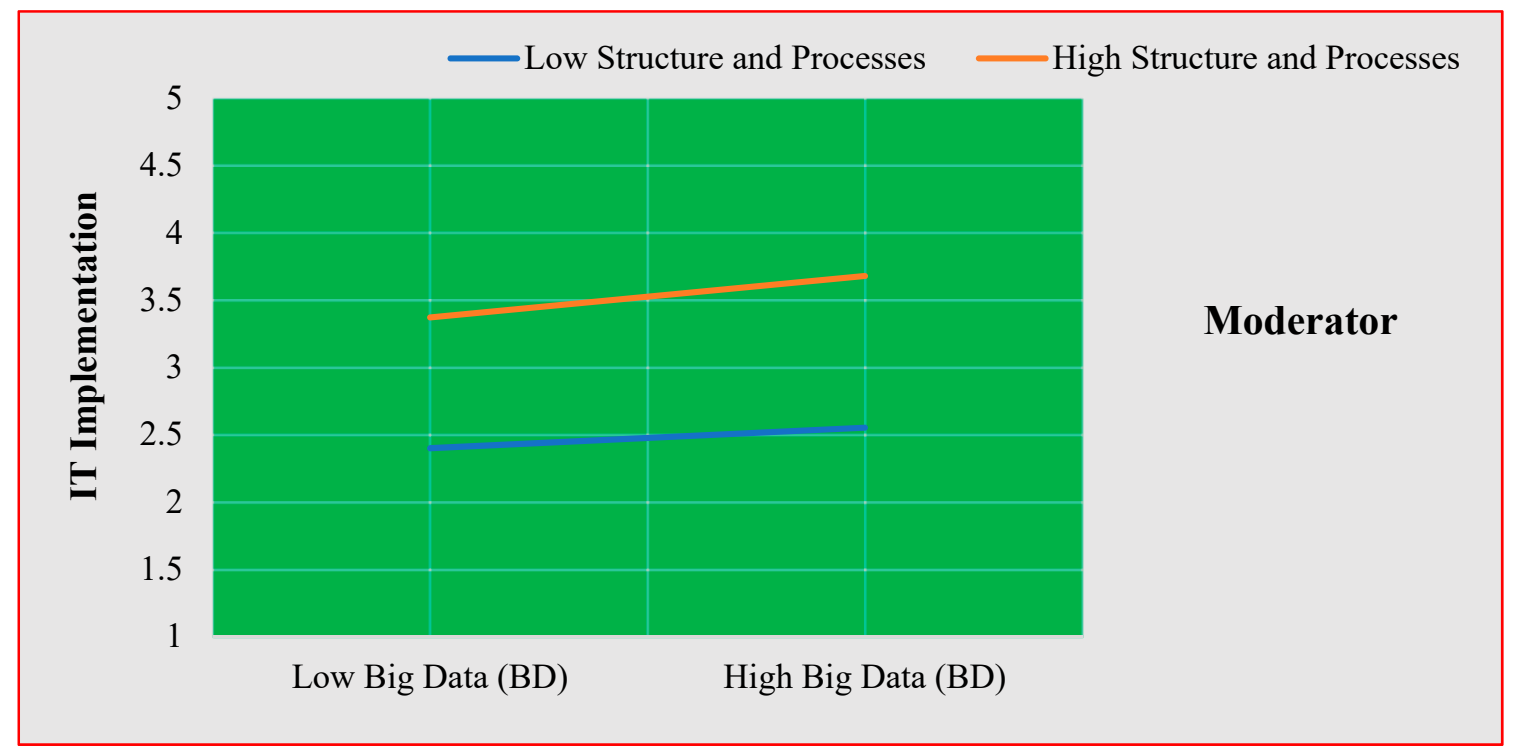

Figure 10. Moderation effect of structure and processes between big data (BD) and IT implementation which is strengthening the relationship.

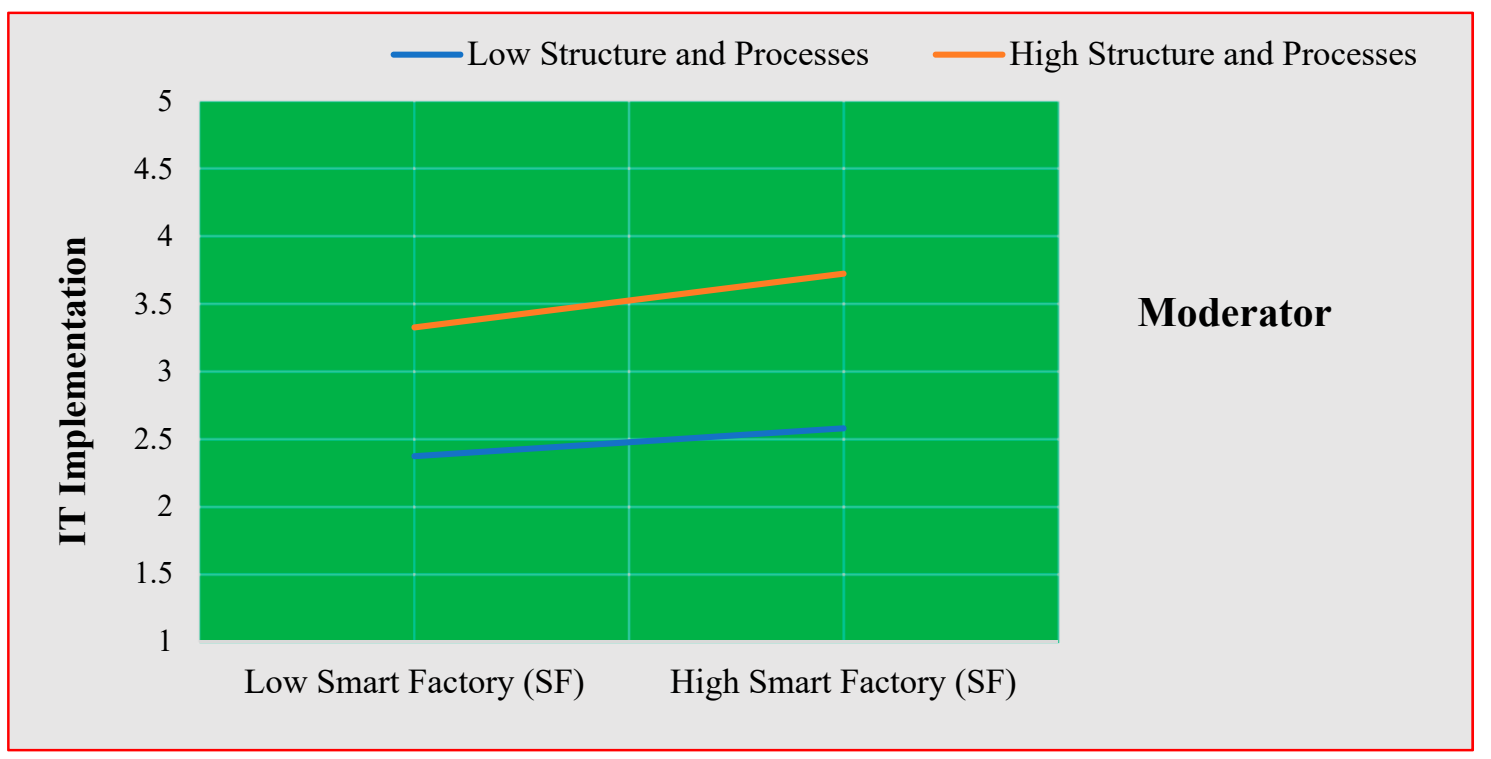

Figure 11. Moderation effect of structure and processes between smart factory (SF) and IT implementation which is strengthening the relationship.

Figure 10 shows that structure and processes as a moderating variable strengthen the relationship between big data (BD) and IT implementation. Consistent with these results, Figure 11 shows that structure and processes as a moderating variable strengthen the relationship between smart factory (SF) and IT implementation. Therefore, insufficient or unsuitable structures and processes can affect negatively on the success of IT in firms (Delone and McLean 2003). Structure and process of an organization show a strong relationship with IT implementation (Heracleous and Barrett 2001).

\section{Conclusions}

The objective of this study is to identify the role of Industry 4.0 to promote sustainable business performance in Thailand's SMEs as the Thai SMEs are facing various technology challenges. This study has attempted to address the solution of various technology challenges through Industry 4.0. The study considers three major elements of Industry 4.0, big data, IoT and smart factory. This study has examined 
how big data, IoT and smart factory are helpful in IT implementation. Additionally, this study reveals the role of organization structure and processes in IT implementation. To achieve this, a cross-sectional research design is used for a survey.

Findings reveal that Industry 4.0 is key to the growth of sustainable business performance among SMEs. Elements of Industry 4.0 such as big data, Internet of Things and smart factory have a positive role in promoting information technology (IT) implementation, which contributes to sustainable business performance. Big data, IoT and smart factory help to implement new technology. Implementation of new technology enhances business performance. However, for the implementation of new technology and to benefit from Industry 4.0, the structure and process of the organization must be supportive. If the structure and process of organization are not supportive, it will create the constraint in the way of technology implementation and affect negatively on sustainable business performance.

\subsection{Limitation of the Study}

The current study provides valuable insights for practitioners; however, this study also has limitations. As the study is limited to Thai SMEs, therefore, the results cannot be generalized, because the business environment in each country is different based on competition and resources. Thus, it is quite difficult to apply the results of the current study in any other business environment. Moreover, this study is based on survey questionnaires which is one of the limitations of this study. Because, face to face interviews with employee of SMEs may provide the better outcomes. Another limitation of this study is that, since Industry 4.0 has latest technology, therefore, due to lack of resources, SMEs are unable to implement Industry 4.0 completely, in this case the results can be better obtained by applying the current model on High-Tech SMEs.

\subsection{Future Research}

This study used survey questionnaires in which face to face interaction with managerial employees was not possible. Therefore, the future research should be carried out with the help of a mixed method approach. The interviews with managers may lead to the better results. Moreover, since the small-scale SMEs have limited resources, therefore, the current model should be applied on High-Tech SMEs. Additionally, future research should consider other elements of Industry 4.0 such as interoperability and cyber physical system.

\subsection{Implications of the Study}

How to overcome the technical challenges in organizations is one of the important questions, and it urges the organizations to investigate the possible ways. In this way, the current study is most significant for organizations to handle various technology-related issues. This study is beneficial for practitioners to overcome different issues of data handling and increase efficiency. Therefore, by taking help from the current study, the organizations may solve various issues. Notably, this study is beneficial for Thai SMEs. Theoretically, this is one of the first studies to deal the relationship between Industry 4.0 and technology challenges with the help of the survey. Thus, this study provides a survey-based platform to use Industry 4.0 as a remedy to overcome various technical challenges. Moreover, as this study contributed in the body of knowledge by examining the role of Industry 4.0 in technology management and the current study is one of the pioneer studies which discussed the role of Industry 4.0 in technology management, this study opens new discussion for scholars. This study adds to the empirical literature by investigating the role of Industry 4.0 in technology management which is more effective to conduct future research in the field of the fourth industrial revolution.

\subsection{Policy Recommendation}

It is always difficult to solve various challenges related to the latest technology, especially for those organizations with minimal resources, such as SMEs. In this direction, this study is recommended to the Thai SMEs to manage technology issues with the help of Industry 4.0 features. 
It is recommended that the Thai SMEs implement the big data technology, IoT and smart factory to manage issues. Better implementation of these elements has the ability to manage various challenges. Before implementation of these technologies, SMEs must develop a supportive culture and infrastructure to support new technology.

Author Contributions: Conceptualization, M.H.; Data curation, H.I.H.; Formal analysis, H.I.H.; Investigation, M.H. and B.Ś.; Methodology, B.Ś.; Resources, M.H.; Software, M.H.; Writing—original draft, M.H.; Writing—review \& editing, K.J.

Funding: This research received no external funding.

Conflicts of Interest: The authors declare no conflict of interest.

\section{References}

Acs, Zoltan J., and Lee Preston. 1997. Small and Medium-Sized Enterprises, Technology, and Globalization: Introduction to a Special Issue on Small and Medium-Sized Enterprises in the Global Economy. Small Business Economics 9: 1-6. [CrossRef]

Ali, Azlan, and Muhammad Haseeb. 2019. Radio frequency identification (RFID) technology as a strategic tool towards higher performance of supply chain operations in textile and apparel industry of Malaysia. Uncertain Supply Chain Management 7: 215-26. [CrossRef]

Ali, Bejjar Mohamed, and Boujelbene Younes. 2013. The impact of information systems on user performance: An exploratory study. Journal of Knowledge Management, Economics and Information Technology 3: 128-54.

Al-Majali, Dmaithan A. 2011. Antecedents of It-Business Alignment Factors in Influencing Sustainable Competitive Advantage. Kedah: Universiti Utara Malaysia.

Ashton, Kevin. 2009. That 'Internet of Things' Thing. RFID Journal 22: 97-114.

Bharadwaj, Anandhi S. 2000. A Resource-Based Perspective on Information Technology Capability and Firm Performance: An Empirical Investigation. MIS Quarterly 24: 169-96. [CrossRef]

Brettel, Malte, Niklas Friederichsen, Michael Keller, and Marius Rosenberg. 2014. How Virtualization, Decentralization and Network Building Change the Manufacturing Landscape: An Industry 4.0 Perspective. International Journal of Mechanical, Industrial Science and Engineering 8: 37-44.

Brown, Carol V., and Sharon L. Magill. 1994. Alignment of the Is Functions with the Enterprise: Toward a Model of Antecedents. MIS Quarterly 18: 371-403. [CrossRef]

Brynjolfsson, Erik, and Lorin Hitt. 1996. Paradox lost? Firm-level evidence on the returns to information systems spending. Management Science 42: 541-58. [CrossRef]

Brynjolfsson, Erik, and Lorin M. Hitt. 2000. Beyond Computation: Information Technology, Organizational Transformation and Business Performance. Journal of Economic Perspectives 14: 23-48. [CrossRef]

Burgess, Stephen. 2001. Managing Information Technology in Small Business: Challenges and Solutions. Hershey: IGI Global.

Chaudhry, Theresa, Muhammad Haseeb, and Maryiam Haroon. 2017. Economic geography and misallocation in Pakistan's manufacturing hub. Annals of Regional Science 59: 189-208. [CrossRef]

Chen, Zhen, and Mingjie Xing. 2015. Upgrading of Textile Manufacturing Based on Industry 4.0. Paper presented at the 5th International Conference on Advanced Design and Manufacturing Engineering, Shenzhen, China, September 19-20.

Chin, Wynne W. 1998. The Partial Least Squares Approach to Structural Equation Modeling. Modern Methods for Business Research 295: 295-336.

Chittithaworn, Chuthamas, Md Aminul Islam, Thiyada Keawchana, and Dayang Hasliza Muhd Yusuf. 2011. Factors Affecting Business Success of Small \& Medium Enterprises (Smes) in Thailand. Asian Social Science 7: 180-90.

Craighead, C. W., and R. L. Laforge. 2003. Taxonomy of Information Technology Adoption Patterns in Manufacturing Firms. International Journal of Production Research 41: 2431-49. [CrossRef]

Dachyar, M., and S. A. Risky. 2014. Improving Operational System Performance of Internet of Things (Iot) in Indonesia Telecomunication Company. IOP Conference Series: Materials Science and Engineering 58: 012014. [CrossRef] 
de Sousa, Jabbour, Ana Beatriz Lopes, Charbel Jose Chiappetta Jabbour, Cyril Foropon, and Moacir Godinho Filho. 2018. When Titans Meet-Can Industry 4.0 Revolutionise the Environmentally-Sustainable Manufacturing Wave? The Role of Critical Success Factors. Technological Forecasting and Social Change 132: 18-25. [CrossRef]

Del Giudice, Manlio. 2016. Discovering the Internet of Things (Iot) within the Business Process Management: A Literature Review on Technological Revitalization. Business Process Management Journal 22: 263-70. [CrossRef]

Delone, William H., and Ephraim R. McLean. 2003. The Delone and Mclean Model of Information Systems Success: A Ten-Year Update. Journal of Management Information Systems 19: 9-30.

Dhar, Subhankar, and Sourav Mazumdar. 2014. Challenges and Best Practices for Enterprise Adoption of Big Data Technologies. Paper presented at the 2014 IEEE International Technology Management Conference, Chicago, IL, USA, June 12-15.

Dobrovič, Jan, Urbański Mariusz, Gallo Peter, Benková Eva, and Čabinová Veronika. 2018. Balanced scorecard concept as a tool of strategic management and its usage in the construction industry. Polish Journal of Management Studies 18: 59-72. [CrossRef]

Dos Santos, Brian L., Ken Peffers, and David C. Mauer. 1993. The Impact of Information Technology Investment Announcements on the Market Value of the Firm. Information Systems Research 4: 1-23. [CrossRef]

Durana, Pavol, Pavol Kral, Vojtech Stehel, George Lazaroiu, and Wlodzimierz Sroka. 2019. Quality Culture of Manufacturing Enterprises: A Possible Way to Adaptation to Industry 4.0. Social Sciences 8: 124. [CrossRef]

Duygulu, Ethem, Emir Ozeren, Pınar Işıldar, and Andrea Appolloni. 2016. The Sustainable Strategy for Small and Medium Sized Enterprises: The Relationship between Mission Statements and Performance. Sustainability 8: 698. [CrossRef]

Dweekat, Abdallah Jamal, Gyusun Hwang, and Jinwoo Park. 2017. A Supply Chain Performance Measurement Approach Using the Internet of Things: Toward More Practical Scpms. Industrial Management E Data Systems 117: 267-86.

Eisingerich, Andreas B., and Simon J. Bell. 2008. Perceived Service Quality and Customer Trust: Does Enhancing Customers' Service Knowledge Matter? Journal of Service Research 10: 256-68. [CrossRef]

Epelbaum, Freddy Moises Brofman, and Marian Garcia Martinez. 2014. The Technological Evolution of Food Traceability Systems and Their Impact on Firm Sustainable Performance: A Rbv Approach. International Journal of Production Economics 150: 215-24. [CrossRef]

Etuk, Reuben Ufot, Grace Reuben Etuk, and Baghebo Michael. 2014. Small and Medium Scale Enterprises (Smes) and Nigeria's Economic Development. Mediterranean Journal of Social Sciences 5: 656. [CrossRef]

Fasanghari, Mehdi, Shooresh Mohammadi, Mehdi Khodaei, Ali Abdollahi, and Farzad Habibipour Roudsari. 2007. A Conceptual Framework for Impact of Information Technology on Supply Chain Management. Paper presented at the 2007 International Conference on Convergence Information Technology (ICCIT 2007), Gyeongju, Korea, November 21-23.

Feeny, David F., and Leslie P. Willcocks. 1998. Core Is Capabilities for Exploiting Information Technology. Sloan Management Review 39: 9-21.

Flügel, Christian, and Volker Gehrmann. 2008. Scientific Workshop 4: Intelligent Objects for the Internet of Things: Internet of Things-Application of Sensor Networks in Logistics. Paper presented at the European Conference on Ambient Intelligence 2008, Nuremberg, Germany, November 19-22.

Fortino, Giancarlo, and Paolo Trunfio. 2014. Internet of Things Based on Smart Objects: Technology, Middleware and Applications. Berlin and Heidelberg: Springer.

Georgakopoulos, Dimitrios, Prem Prakash Jayaraman, Maria Fazia, Massimo Villari, and Rajiv Ranjan. 2016. Internet of Things and Edge Cloud Computing Roadmap for Manufacturing. IEEE Cloud Computing 3: 66-73. [CrossRef]

Ghobakhloo, Morteza, and Tang Sai Hong. 2014. It Investments and Business Performance Improvement: The Mediating Role of Lean Manufacturing Implementation. International Journal of Production Research 52: 5367-84. [CrossRef]

Gu, Min, Xiangping Li, and Yaoyu Cao. 2014. Optical Storage Arrays: A Perspective for Future Big Data Storage. Light: Science \& Applications 3: e177.

Gubbi, Jayavardhana, Rajkumar Buyya, Slaven Marusic, and Marimuthu Palaniswami. 2013. Internet of Things (IoT): A Vision, Architectural Elements, and Future Directions. Future Generation Computer Systems 29: 1645-60. [CrossRef] 
Hair, Joe, Carole L. Hollingsworth, Adriane B. Randolph, and Alain Yee Loong Chong. 2017. An Updated and Expanded Assessment of Pls-Sem in Information Systems Research. Industrial Management E Data Systems 117: 442-58.

Hameed, Waseem-Ul, Faiza Hashmi, Mohsin Ali, and Muhammad Arif. 2017. Enterprise Risk Management (Erm) System: Implementation Problem and Role of Audit Effectiveness in Malaysian Firms. Asian Journal of Multidisciplinary Studies 5: 11.

Hariharasudan, A., and Sebastian Kot. 2018. A Scoping Review on Digital English and Education 4.0 for Industry 4.0. Social Sciences 7: 227. [CrossRef]

Hashem, Ibrahim Abaker Targio, Ibrar Yaqoob, Nor Badrul Anuar, Salimah Mokhtar, Abdullah Gani, and Samee Ullah Khan. 2015. The Rise of "Big Data" on Cloud Computing: Review and Open Research Issues. Information Systems 47: 98-115. [CrossRef]

$\mathrm{He}, \mathrm{Wu}$, Gongjun Yan, and Li Da Xu. 2014. Developing Vehicular Data Cloud Services in the Iot Environment. IEEE Transactions on Industrial Informatics 10: 1587-95. [CrossRef]

Henderson, John C., and Harihara Venkatraman. 1999. Strategic Alignment: Leveraging Information Technology for Transforming Organizations. IBM Systems Journal 38: 472-84. [CrossRef]

Henning, Kagermann. 2013. Recommendations for Implementing the Strategic Initiative Industrie 4.0. Acatech. Washington, DC: National Academy of Science and Engineering.

Heracleous, Loizos, and Michael Barrett. 2001. Organizational Change as Discourse: Communicative Actions and Deep Structures in the Context of Information Technology Implementation. Academy of Management Journal 44: 755-78.

Hermann, Mario, Tobias Pentek, and Boris Otto. 2016. Design Principles for Industrie 4.0 Scenarios. Paper presented at the 2016 49th Hawaii International Conference on System Sciences (HICSS), Kauai, HI, USA, January 5-8.

Hitt, Lorin M., and Erik Brynjolfsson. 1996. Productivity, Business Profitability, and Consumer Surplus: Three Different Measures of Information Technology Value. MIS Quarterly 20: 121-42. [CrossRef]

Ho, Chin-Fu. 1996. Information Technology Implementation Strategies for Manufacturing Organizations: A Strategic Alignment Approach. International Journal of Operations E Production Management 16: 77-100.

Hoque, Faisal, Lawrence Walsh, Diana Mirakaj, and Jeffrey Bruckner. 2011. The Power of Convergence: Linking Business Strategies and Technology Decisions to Create Sustainable Success. New York: Amacom.

Huang, Cheng-Kui. 2015. Market Reaction to Big Data Implementation Announcements. Available online: https://ssrn.com/abstract=2563990 (accessed on 13 May 2019).

Huang, Cheng-Kui. 2016. The Impact of Big Data Implementation on Firm Performance. Master's thesis, Department of Business Administration, National Chung Cheng University, Chiayi County, Taiwan.

Ilegbinosa, Imoisi Anthony, and Ephraim Jumbo. 2015. Small and Medium Scale Enterprises and Economic Growth in Nigeria: 1975-2012. International Journal of Business and Management 10: 203-16. [CrossRef]

Imran, Muhammad, Waseem Hameed, and Adnan Haque. 2018. Influence of Industry 4.0 on the Production and Service Sectors in Pakistan: Evidence from Textile and Logistics Industries. Social Sciences 7: 246. [CrossRef]

Industrial Internet Consortium. 2017. A Global Industry First: Industrial Internet Consortium and Plattform Industrie 4.0 to Host Joint IIoT Security Demonstration at Hannover Messe 2017. Available online: https://www.iiconsortium.org/press-room/04-20-17.htm (accessed on 13 May 2019).

Javanmardi, M., A. Khabushani, and A. Abdi. 2012. Analysis Information Technology Infrastructures toward Supply Chain Agility in Home Appliance Industry. Interdisciplinary Journal of Contemporary Research in Business 4: 416-29.

Jeffers, Patrick I., Waleed A. Muhanna, and Barrie R. Nault. 2008. Information Technology and Process Performance: An Empirical Investigation of the Interaction between It and Non-It Resources. Decision sciences 39: 703-35. [CrossRef]

Jones, Derek, and Takao Kato. 2003. The Effects of Employee Involvement on Firm Performance: Evidence from an Econometric Case Study. SSRN Electronic Journal. [CrossRef]

Joshi, Gyanendra Prasad, and Sung Won Kim. 2008. Survey, Nomenclature and Comparison of Reader Anti-Collision Protocols in Rfid. IETE Technical Review 25: 234-43. [CrossRef]

Kanellis, Panagiotis, Mark Lycett, and Ray J. Paul. 1999. Evaluating Business Information Systems Fit: From Concept to Practical Application. European Journal of Information Systems 8: 65-76. [CrossRef] 
Kihara, Peter, Henry Bwisa, and John Kihoro. 2016. The Role of Technology in Strategy Implementation and Performance of Manufacturing Small and Medium Firms in Thika, Kenya. International Journal of Business and Social Science 7: 156-165.

Kim, Kyung Kyu, Ho Lee, and Young Jin Park. 2011. Interorganizational Information Systems Asymmetry and Supply Chain Performance. Paper presented at the The 5th International Conference on New Trends in Information Science and Service Science, Macao, China, October 24-26.

Kolberg, Dennis, and Detlef Zühlke. 2015. Lean Automation Enabled by Industry 4.0 Technologies. IFAC-PapersOnLine 48: 1870-75. [CrossRef]

Kristensen, Kai, and Anders H. Westlund. 2004. Accountable Business Performance Measurement for Sustainable Business Excellence. Total Quality Management \& Business Excellence 15: 629-43.

Kube, Georg, and Thomas Rinn. 2014. Industry 4.0-the Next Revolution in the Industrial Sector. Gutersloh: Bauverlag bv Gmbh.

Langer, Steve G. 2011. Challenges for Data Storage in Medical Imaging Research. Journal of Digital Imaging 24: 203-7. [CrossRef]

Lasi, Heiner, Peter Fettke, Hans-Georg Kemper, Thomas Feld, and Michael Hoffmann. 2014. Industry 4.0. Business $\mathcal{E}$ Information Systems Engineering 6: 239-42.

Lin, Feilong, Cailian Chen, Ning Zhang, Xinping Guan, and Xuemin Shen. 2016. Autonomous Channel Switching: Towards Efficient Spectrum Sharing for Industrial Wireless Sensor Networks. IEEE Internet of Things Journal 3: 231-43. [CrossRef]

Lloyd, Hendrik. 2002. Small and Medium Enterprises (SMEs): Instruments of Economic Growth and Development in a South African Regional Dispensation. Louvain-la-Neuve: European Regional Science Association.

Lu, Yang. 2017. Industry 4.0: A Survey on Technologies, Applications and Open Research Issues. Journal of Industrial Information Integration 6: 1-10. [CrossRef]

Lukač, Duško. 2015. The Fourth Ict-Based Industrial Revolution "Industry 4.0"-Hmi and the Case of Cae/Cad Innovation with Eplan P8. Paper presented at the 2015 23rd Telecommunications Forum Telfor (TELFOR), Belgrade, Serbia, November 24-26.

Lynch, Clifford. 2008. Big Data: How Do Your Data Grow? Nature 455: 28-29. [CrossRef] [PubMed]

Malhotra, Yogesh. 2005. Integrating Knowledge Management Technologies in Organizational Business Processes: Getting Real Time Enterprises to Deliver Real Business Performance. Journal of Knowledge Management 9: 7-28. [CrossRef]

Manyika, James, Michael Chui, Brad Brown, Jacques Bughin, Richard Dobbs, Charles Roxburgh, and Angela H. Byers. 2011. Big Data: The Next Frontier for Innovation, Competition, and Productivity. New York: McKinsey Global Institute.

Marginson, David, Malcolm King, and Laurie McAulay. 2000. Executives' Use of Information Technology: Comparison of Electronic Mail and an Accounting Information System. Journal of Information technology 15: 149-64.

Moshiri, Saeed, and Wayne Simpson. 2011. Information Technology and the Changing Workplace in Canada: Firm-Level Evidence. Industrial and Corporate Change 20: 1601-36. [CrossRef]

Nagy, Judit, Judit Oláh, Edina Erdei, Domicián Máté, and József Popp. 2018. The role and impact of industry 4.0 and the Internet of Things on the business strategy of the value chain-the case of Hungary. Sustainability 10: 3491. [CrossRef]

Nawanir, Gusman. 2016. The Effect of Lean Manufacturing on Operations Performance and Business Performance in Manufacturing Companies in Indonesia. Kedah: Universiti Utara Malaysia.

Omar, Roaimah, Suhaiza Zailani, Mohamed Sulaiman, and T. Ramayah. 2006. Supplier Involvement, Customer Focus, Supply Chain Technology and Manufacturing Performance: Findings from a Pilot Study. Paper presented at the 2006 IEEE International Conference on Management of Innovation and Technology, Singapore, June 21-23.

Oses, Noelia, Aritz Legarretaetxebarria, Marco Quartulli, Igor García, and Mikel Serrano. 2016. Uncertainty Reduction in Measuring and Verification of Energy Savings by Statistical Learning in Manufacturing Environments. International Journal on Interactive Design and Manufacturing (IJIDeM) 10: 291-99. [CrossRef]

Paelke, Volker. 2014. Augmented Reality in the Smart Factory: Supporting Workers in an Industry 4.0 Environment. Paper presented at the 2014 IEEE Emerging Technology and Factory Automation (ETFA), Barcelona, Spain, September 16-19. 
Pang, Zhibo. 2013. Technologies and Architectures of the Internet-of-Things (Iot) for Health and Well-Being. Stockholm: KTH Royal Institute of Technology.

Patel, Keyur K., and Sunil M. Patel. 2016. Internet of Things-Iot: Definition, Characteristics, Architecture, Enabling Technologies, Application \& Future Challenges. International Journal of Engineering Science and Computing 6: 6122-31.

Peppard, Joe, and John Ward. 2004. Beyond Strategic Information Systems: Towards an Is Capability. The Journal of Strategic Information Systems 13: 167-94. [CrossRef]

Pfeiffer, Sabine. 2016. Robots, Industry 4.0 and Humans, or Why Assembly Work Is More Than Routine Work. Societies 6: 16. [CrossRef]

Pisching, Marcos A., Fabrício Junqueira, Diolino J. Santos Filho, and Paulo E. Miyagi. 2015. Service Composition in the Cloud-Based Manufacturing Focused on the Industry 4.0. Paper presented at the Doctoral Conference on Computing, Electrical and Industrial Systems, Costa de Caparica, Portugal, April 13-15.

Posada, Jorge, Carlos Toro, Iñigo Barandiaran, David Oyarzun, Didier Stricker, Raffaele de Amicis, Eduardo B. Pinto, Peter Eisert, Jürgen Döllner, and Ivan Vallarino. 2015. Visual Computing as a Key Enabling Technology for Industrie 4.0 and Industrial Internet. IEEE Computer Graphics and Applications 35: 26-40. [CrossRef] [PubMed]

Raguseo, Elisabetta. 2018. Big Data Technologies: An Empirical Investigation on Their Adoption, Benefits and Risks for Companies. International Journal of Information Management 38: 187-95. [CrossRef]

Rashmi, K. V., Nihar B. Shah, Dikang Gu, Hairong Kuang, Dhruba Borthakur, and Kannan. A. Ramchandran. 2013. Solution to the Network Challenges of Data Recovery in Erasure-Coded Distributed Storage Systems: A Study on the Facebook Warehouse Cluster. Paper presented at the Presented as Part of the 5th USENIX Workshop on Hot Topics in Storage and File Systems, San Jose, CA, USA, June 27-28.

Reich, Blaize Horner, and Izak Benbasat. 1990. An Empirical Investigation of Factors Influencing the Success of Customer-Oriented Strategic Systems. Information Systems Research 1: 325-47. [CrossRef]

Reich, Blaize Horner, and Izak Benbasat. 1996. Measuring the Linkage between Business and Information Technology Objectives. MIS Quarterly 20: 55-81. [CrossRef]

Roblek, Vasja, Maja Meško, and Alojz Krapež. 2016. A Complex View of Industry 4.0. SAGE Open 6. [CrossRef]

Rüßmann, Michael, Markus Lorenz, Philipp Gerbert, Manuela Waldner, Jan Justus, Pascal Engel, and Michael Harnisch. 2015. Industry 4.0: The Future of Productivity and Growth in Manufacturing Industries. Boston Consulting Group 9: 54-89.

Sabherwal, Rajiv, and Peeter Kirs. 1994. The Alignment between Organizational Critical Success Factors and Information Technology Capability in Academic Institutions. Decision Sciences 25: 301-30. [CrossRef]

Sanders, Adam, Chola Elangeswaran, and Jens P. Wulfsberg. 2016. Industry 4.0 Implies Lean Manufacturing: Research Activities in Industry 4.0 Function as Enablers for Lean Manufacturing. Journal of Industrial Engineering and Management (JIEM) 9: 811-33. [CrossRef]

Scheuermann, Constantin, Stephan Verclas, and Bernd Bruegge. 2015. Agile Factory-An Example of an Industry 4.0 Manufacturing Process. Paper presented at the 2015 IEEE 3rd International Conference on Cyber-Physical Systems, Networks, and Applications, Hong Kong, China, August 19-21.

Sekaran, U., and R. Bougie. 2010. Theoretical Framework in Theoretical Framework and Hypothesis Development. In Research Methods for Business: A Skill Building Approach. Haddington: John Wiley \& Sons.

Shafiq, Syed Imran, Cesar Sanin, Edward Szczerbicki, and Carlos Toro. 2016. Virtual Engineering Factory: Creating Experience Base for Industry 4.0. Cybernetics and Systems 47: 32-47. [CrossRef]

Shpak, Nestor, Liliya Satalkina, Wlodzimierz Sroka, and Stefan Hittmar. 2017. The social direction of enterprises' innovation activity. Polish Journal of Management Studies 16: 187-201. [CrossRef]

Shrouf, Fadi, Joaquin Ordieres, and Giovanni Miragliotta. 2014. Smart Factories in Industry 4.0: A Review of the Concept and of Energy Management Approached in Production Based on the Internet of Things Paradigm. Paper presented at the 2014 IEEE International Conference on Industrial Engineering and Engineering Management, Bandar Sunway, Malaysia, December 9-12.

Skivington, James E., and Richard L. Daft. 1991. A Study of Organizational 'Framework'and 'Process'modalities for the Implementation of Business-Level Strategic Decisions. Journal of Management Studies 28: 45-68. [CrossRef]

Stock, Tim, and Seliger Günther. 2016. Opportunities of Sustainable Manufacturing in Industry 4.0. Procedia CIRP 40: 536-41. [CrossRef] 
Suresh, P., J. Vijay Daniel, V. Parthasarathy, and R. H. Aswathy. 2014. A State of the Art Review on the Internet of Things (Iot) History, Technology and Fields of Deployment. Paper presented at the 2014 International Conference on Science Engineering and Management Research (ICSEMR), Chennai, India, Nocember 27-29.

Szczepańska-Woszczyna, Katarzyna. 2014. The importance of organizational culture for innovation in the company. Forum Scientiae Oeconomia 2: 27-39.

Šavareikienè, Danguolè, and Galinytė Rasa. 2018. Self-service as a motivation factor for innovative service. Forum Scientiae Oeconomia 6: 33-46.

Ślusarczyk, Beata. 2018. Industry 4.0: Are we ready? Polish Journal of Management Studies 17: 232-48. [CrossRef]

Tang, Chia-Pei, Tony Cheng-Kui Huang, and Szu-Ting Wang. 2018. The Impact of Internet of Things Implementation on Firm Performance. Telematics and Informatics 35: 2038-53. [CrossRef]

Thames, Lane, and Dirk Schaefer. 2016. Software-Defined Cloud Manufacturing for Industry 4.0. Procedia CIRP 52: 12-17. [CrossRef]

Thamsen, Paul Uwe, and Sebastian Wulff. 2016. Achema-Nachbericht: Industrie 4.0 Und Aktuelle Trends in Der Pumpenindustrie-Ein Rückblick Auf Die Achema 2015. Chemie Ingenieur Technik 88: 15-19. [CrossRef]

Varghese, Anitha, and Tandur Deepaknath. 2014. Wireless Requirements and Challenges in Industry 4.0. Paper presented at the 2014 International Conference on Contemporary Computing and Informatics (IC3I), Mysore, India, November 27-29.

Vogel-Heuser, Birgit, and Dieter Hess. 2016. Guest Editorial Industry 4.0-Prerequisites and Visions. IEEE Transactions on Automation Science and Engineering 13: 411-13. [CrossRef]

Wan, Jiafu, Shenglong Tang, Zhaogang Shu, Di Li, Shiyong Wang, Muhammad Imran, and Athanasios V. Vasilakos. 2016. Software-Defined Industrial Internet of Things in the Context of Industry 4.0. IEEE Sensors Journal 16: 7373-80. [CrossRef]

Wang, Chung-Jen. 2014. Do Ethical and Sustainable Practices Matter? Effects of Corporate Citizenship on Business Performance in the Hospitality Industry. International Journal of Contemporary Hospitality Management 26: 930-47. [CrossRef]

Wang, Shiyong, Jiafu Wan, Daqiang Zhang, Di Li, and Chunhua Zhang. 2016. Towards Smart Factory for Industry 4.0: A Self-Organized Multi-Agent System with Big Data Based Feedback and Coordination. Computer Networks 101: 158-68. [CrossRef]

Waschneck, Bernd, Thomas Altenmüller, Thomas Bauernhansl, and Andreas Kyek. 2016. Production Scheduling in Complex Job Shops from an Industry 4.0 Perspective: A Review and Challenges in the Semiconductor Industry. Paper presented at the SAMI@ iKNOW, Graz, Austria, October 18-19.

Weyer, Stephan, Mathias Schmitt, Moritz Ohmer, and Dominic Gorecky. 2015. Towards Industry 4.0-Standardization as the Crucial Challenge for Highly Modular, Multi-Vendor Production Systems. IFAC-PapersOnLine 48: 579-84. [CrossRef]

$\mathrm{Xu}$, Li Da, and Lian Duan. 2019. Big Data for Cyber Physical Systems in Industry 4.0: A Survey. Enterprise Information Systems 13: 148-69. [CrossRef]

Yang, Kan, and Xiaohua Jia. 2012. Data Storage Auditing Service in Cloud Computing: Challenges, Methods and Opportunities. World Wide Web 15: 409-28. [CrossRef]

Yun, Miao, and Yuxin Bu. 2010. Research on the Architecture and Key Technology of Internet of Things (Iot) Applied on Smart Grid. Paper presented at the 2010 International Conference on Advances in Energy Engineering, Beijing, China, June 19-20.

Zawadzki, Przemysław, and Krzysztof Żywicki. 2016. Smart Product Design and Production Control for Effective Mass Customization in the Industry 4.0 Concept. Management and Production Engineering Review 7: 105-12. [CrossRef]

Zikopoulos, Paul, Dirk Deroos, Krishnan Parasuraman, Thomas Deutsch, James Giles, and David Corrigan. 2013. Harness the Power of Big Data: The Ibm Big Data Platform. New York: McGraw-Hill.

(C) 2019 by the authors. Licensee MDPI, Basel, Switzerland. This article is an open access article distributed under the terms and conditions of the Creative Commons Attribution (CC BY) license (http://creativecommons.org/licenses/by/4.0/). 